\title{
Peptide Conjugate Hydrogelators
}

\author{
Dave J. Adams ${ }^{\mathrm{a}}$ and Paul D. Topham ${ }^{\mathrm{b}}$ \\ Received (in $X X X, X X X)$ Xth $X X X X X X X X X 200 X$, Accepted Xth $X X X X X X X X X 200 X$ \\ First published on the web Xth $X X X X X X X X X 200 X$ \\ ${ }_{5}$ DOI: 10.1039/b000000x
}

Molecular gelators are currently receiving a great deal of attention. These are small molecules which, under the appropriate conditions, assemble in solution to, in the majority of cases, give long fibrillar structures which entangle to form a three-dimensional network. This immobilises the solvent, resulting in a gel. Such gelators have potential application in a number of important areas

10 from drug delivery to tissue engineering. Recently, the use of peptide-conjugates has become prevalent with oligopeptides (from as short as two amino acids in length) conjugated to a polymer, alkyl chain or aromatic group such as naphthalene or fluorenylmethoxycarbonyl (Fmoc) being shown to be effective molecular gelators. The field of gelation is extremely large; here we will focus our attention on the use of these peptide-conjugates as molecular hydrogelators.

\section{${ }_{15}$ 1. Introduction}

\subsection{Hydrogels}

Hydrogels comprise a water phase immobilised by a scaffold. ${ }^{1-3}$ This scaffold gives structure to the aqueous phase and results in a gel. Hydrogels are of wide interest due to the

20 biocompatibility of the systems with applications in areas such as drug delivery (where either the scaffold or aqueous pool can be used as a reservoir for other components ${ }^{4-6}$ ), tissue engineering (where hydrogels are used as 3D scaffolds to support the growth of cultured cells, mimicking the 25 extracellular matrix), ${ }^{7-22}$ biomineralisation $^{23}$ and contact lenses. ${ }^{24,25}$ The scaffold can be formed in a number of ways. Often, polymeric scaffolds are used. These can be naturally occurring polymers such as polysaccharides (including pectin and alginate ${ }^{26,27}$ ) or synthetic polymers such as cross-linked 30 poly(ethylene oxide) (PEO) or poly(hydroxyethylmethacrylate). ${ }^{28}$ In these latter cases, the polymers, which are water soluble, are induced to form a nonsoluble matrix by cross-linking. This cross-linking is usually carried out by the incorporation of a nominal quantity of 35 bifunctional monomer with UV radiation or redox initiated chemistry. Depending on the application, this method can have drawbacks. For example, if cells are to be encapsulated in the gels, the radicals present during the polymerisation can cause damage to cells. ${ }^{29}$ Additionally, this cross-linking step 40 often means that in those cases where encapsulation is required, the drug or other encapsulant molecule has to be added post-cross-linking to avoid reaction with the monomers or cross-linker. An alternative strategy is to make use of low molecular weight compounds that assemble in solution in such 45 a way as to form a network of fibres, Figure 1. This strategy is currently generating interest, particularly when using peptidebased molecules, which drive the gelation at relatively low concentrations.

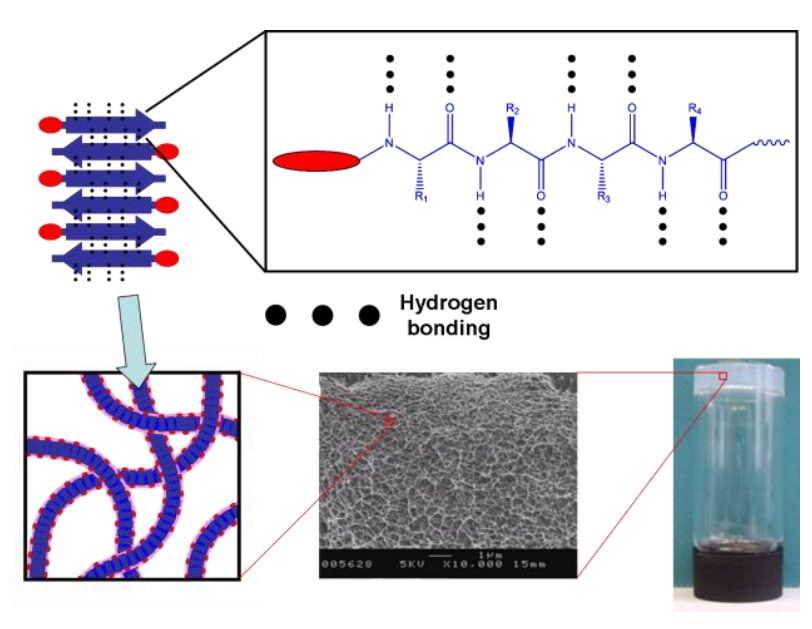

Figure 1. Assembly of peptide-conjugates in water via noncovalent forces (including hydrogen-bonding, electrostatics, $\pi$-stacking and hydrophobicity) leads to the formation of fibrous structures. In this example, anti-parallel $\beta$-sheets are 60 formed between the peptide-conjugates. Entanglement of these fibres leads to a three-dimensional network which immobilises the water, resulting in a hydrogel as demonstrated by the lack of flow on vial inversion.

\section{${ }_{65}$ 1.2. Peptide-based self-assembled systems}

A large number of molecules are known to be capable of forming one-dimensional fibres which then entangle to form the matrix of the gel. The design rules for what will or will not form a network remain unclear, ${ }^{30}$ with often very similar 70 compounds having very different behaviour. Nonetheless, it is known that the fibres are formed via assembly through noncovalent forces such as hydrogen-bonding, $\pi$-stacking, electrostatics and hydrophobic forces and are formed when the precise balance of hydrophilicity and hydrophobicity is 75 present. Individually, these interactions are quite weak. 
Collectively, however, they can give rise to extremely stable structures. $^{31}$ Within these forces, there are different requirements. Hydrogen-bonding requires precisely positioned donors and acceptors. In peptidic systems, depending on the 5 sequence of amino acids, hydrogen-bonding can lead to the formation of ordered secondary structures including $\alpha$-helices, $\beta$-sheets and anti-parallel $\beta$-sheets. Efficient $\pi$-stacking requires the overlapping of aromatic rings being of the order of $3.4 \AA$ apart. On the other hand, electrostatic interactions are 10 not directional and are also more flexible in terms of the distance between the participating charges. Hydrophobic interactions are even less directionally constrained than electrostatic interactions.

Supramolecular hydrogels prepared using these forces have 15 properties which are very different to those arising from cross-linked polymer hydrogels. Since the matrix is held together by non-covalent interaction, the gels tend to have rapid response to chemical or physical stimuli such as $\mathrm{pH}$ and temperature. In addition, on disassembly, the low molecular 20 weight molecules would be expected to be cleared efficiently in vivo, leading to good biodegradability. The concentrations of gelator required are often far lower than for systems using conventional synthetic polymers. As such, there is a higher water content, meaning that such gels are potentially more ${ }_{25}$ biocompatible. $^{32}$ Peptides $^{11}$, 17, 19, 33-49 and polymer-peptide conjugates ${ }^{50-53}$ have emerged as promising gelators since their assembly in water results from such non-covalent forces. Here, we will discuss the use of peptide conjugates as low molecular weight hydrogelators. Specifically, we will discuss 30 the formation of hydrogels using peptides conjugated to a large aromatic group such as naphthalene or Fmoc, peptide amphiphiles (PAs, where a hydrophobic alkyl chain is connected to a hydrophilic peptide) and polymer-peptide conjugates where the peptide block is short or sequence 35 specific. Block copolypeptides are beyond the scope of this review and the reader is directed to the work of Deming. ${ }^{54}$ Protein-based ${ }^{55-57}$ and oligopeptide-based hydrogels are also well-known $^{11,12,39,40,58-62}$ but will not be discussed here. Throughout this review, three letter abbreviations for amino 40 acids will be used.

\section{Material Properties}

An important consideration when designing hydrogels is the target material and mechanical properties for the application in mind. Hydrogels, being primarily composed of water, tend to be 45 weak materials. A number of biological materials are hydrogelbased. For example, cornea is a proteoglycan gel, which contains approximately $20 \%$ collagen fibres. This cartilage has a tensile strength of approximately $4 \mathrm{MPa}{ }^{63}$ For many tissue engineering applications, matching the mechanical properties of the gel with 50 the tissue involved is critical for effective function. ${ }^{10,64,65}$ Gels are also used in drug delivery, where porosity and mesh size are important considerations in addition to the mechanical properties, although these parameters can be closely related (for example, controlling the cross-link density can increase the strength whilst 55 reducing the 'porosity'). ${ }^{66,}{ }^{67}$ Here, triggered release is also an important consideration, thus a stimuli-responsive material is often required. For cell culturing, optimisation of both nutrient diffusion and mechanical properties is vital. ${ }^{6}$ In all of these cases, biocompatibility is of paramount importance.

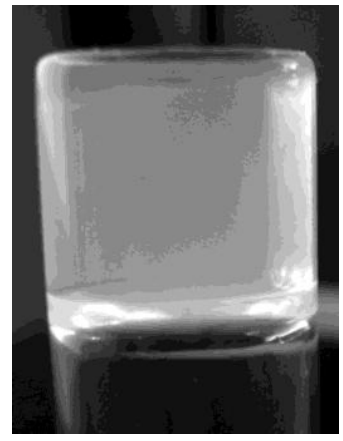

Figure 2. Vial-inversion demonstrating a lack of flow and hence the formation of a gel. Taken from Adams et al. ${ }^{71}$ Reproduced by permission of The Royal Society of Chemistry

Over the years, a number of methods for measuring the material ${ }_{65}$ properties of hydrogels have been developed. ${ }^{69}$ Unlike hydrogels prepared using polymeric scaffolds, gels prepared via the assembly of low molecular weight building blocks can have a very low concentration of scaffold. Consequently, these gels can be difficult to work with. For example, it is commonly impossible 70 to clamp the gels; hence a number of methods for measuring the tensile strength are impossible. For the hydrogels discussed here, therefore, the number of methods used to measure the mechanical properties is limited. First, a significant number of reports make use of what has been described as "Table-top Rheology", based 75 on the concept that "a gel should not flow under the action of a mechanical stress imposed for an infinite period of time". ${ }^{70}$ Hence, simple inversion of a vial can be used to distinguish between a gel and a sol, with the gel showing no flow, Figure 2. Similarly, dense spherical particles can be suspended in physical 80 gels that have appreciable yield stresses. A lack of sedimentation is indicative of a gel, whereas the particles will fall for a viscous liquid. $^{70}$ Whilst useful in determining the phase space for gelation, these methods cannot be used to accurately measure the mechanical properties of the gel. Nonetheless, these methods are 85 the most highly reported in the literature for the demonstration of the formation of a gel. As a result, direct comparison between different systems is often extremely difficult. Additionally, since these methods do not give any information regarding the mechanical properties of the gels, it is often impossible to 90 determine which applications such gels may be suitable for.

Rheological data is available for a number of materials. Rheometry (or rheology) is the science of deformation and flow. ${ }^{72}$ Here, the viscoelastic behaviour of the materials is measured under the application of a stress. The two 95 rheological criteria required for a gel are the independence of the dynamic elastic (or storage) modulus $\left(\mathrm{G}^{\prime}\right)$ on the oscillatory frequency, and that $\mathrm{G}^{\prime}$ exceeds the loss modulus $\left(G^{\prime \prime}\right)$ by approximately one order of magnitude. ${ }^{73} \mathrm{G}^{\prime}$ is an indicator of the elastic behaviour and measures the ability to 100 store deformation energy that can be recovered after removing the load cycle. A number of different measurements can be carried out, including frequency sweeps and strain sweeps, 
where the behaviour of the gel at different frequencies or strains is measured. Typically, for a frequency sweep, the hydrogel is sandwiched between two parallel plates. The top plate is then oscillated backwards and forwards at different 5 frequencies whilst the values of $\mathrm{G}^{\prime}$ and $\mathrm{G}^{\prime \prime}$ are measured. These measurements are routinely carried out, but there are differences between the geometries used to make the measurements (e.g. parallel plates or a vane) and also the way in which the measurements are executed (e.g. some gels are 10 prepared in situ, whereas others are pre-prepared and loaded onto the rheometer). Typical rheological data are shown in Figure 3 for a PEO-peptide hydrogelator at different concentrations. As commonly observed for gels formed via the assembly of low molecular weight gelators, Figure 3a 15 shows that $G^{\prime}$ increases slightly with frequency. Semiflexible network elasticity theories have been used to define the characteristic network and chain dimensions for such systems. ${ }^{74-76}$ In the case of the PEO-peptide shown in Figure 3 , the plateau modulus of the hydrogel scales with the peptide 20 concentration raised to the power 2.4 (i.e. $G^{\prime} \propto c^{2.4}$ ) implying that the increase in $\mathrm{G}^{\prime}$ and $\mathrm{G}^{\prime \prime}$ at higher PEO-peptide concentrations can be ascribed to the increasing degree of entanglement of the nanotubes giving rise to the gel. However, it should be noted that such a concentration 25 dependence is not always observed. Recent results demonstrate that the modulus for a peptide amphiphile hydrogel scales with an exponent of 1.51 or 2.14 depending on the method of self-assembly. ${ }^{77}$ It is likely therefore as more data becomes available that very different types of network 30 are being formed in these systems between which "Table-top rheology" is unable to distinguish.

Some gelators are only prepared on a very small scale, sometimes below the amounts required for rheometry. Here, an alternative is to use microrheology, where the thermal 35 motion of particles embedded in a gel is tracked. ${ }^{78-80}$ Microrheology is sensitive to the low viscoelastic properties at low moduli. Small sample volumes $(<50 \mu \mathrm{L})$ are needed. No external force is applied so there is a minimal risk of disturbing fragile microstructures. However, correlation with 40 rheometric data is uncommon and it is often unclear as to the effect of the embedded particles on the microstructure of the gels. Nevertheless, this can be a useful comparative tool when only small quantities are available.

Information regarding the mesh size of the gels can be 45 determined from measurements on the diffusion of probe molecules within the gel. Measurement of the diffusion rate for molecules of different sizes can be used to probe the network, ${ }^{81,} 82$ although care must be taken as specific interactions between the probe molecules and the network can 50 also affect the diffusion rate. ${ }^{4}$ Recently, proton diffusion has been used to probe the size of the water domains within a selfassembled peptide hydrogel, revealing quantitative information on mesh size. ${ }^{83}$

\section{Synthetic Approaches}

${ }_{55}$ There are a number of different synthetic approaches for producing peptide conjugates, with each process integrating controlled techniques to produce well-defined bio-inspired molecules. The choice of approach is driven by the type of self-assembly mechanism required by the end-user. This 60 review will discuss synthetic approaches that have been used to create the specific gelators discussed above. For more comprehensive reviews and highlights concerning the synthetic techniques employed to fabricate peptide hydrids of varying types, the reader is directed to work by $\mathrm{Kros},{ }^{84}$ ${ }_{65}$ Haddleton $^{85}$ and Klok. ${ }^{86,87}$ Artificial peptide construction is carried out in one of four ways; expression (for generally more complex proteins), ${ }^{88,}{ }^{89} \mathrm{~N}$-carboxyanhydride (NCA) polymerisation (for blocks of homopolypeptides), ${ }^{54}$ solidphase amino acid coupling or solution-phase coupling (both 70 for sequence specific chains). This section briefly compares and contrasts the two amino acid coupling procedures only, as protein expression and NCA polymerisation approaches have not been employed to fabricate the self-assembling molecules discussed in this review (although protein expression has been 75 used to prepare protein-based gelators ${ }^{55-57}$ and NCA polymerisation is used to prepare block copolypeptide gelators ${ }^{54}$ ). Following peptide construction, we move on to discuss the methods of polymer incorporation. Incorporation strategies fall into one of two classes; convergent and 80 divergent syntheses. Convergent methodologies require a conjugation step, where both building blocks are synthesised initially and then coupling together via ligation. Divergent approaches on the other hand require either the modification of the peptide or polymer block (to subsequently allow 85 "growth" of the other component from first moiety) or the conversion of the peptidic component into a macromonomer for subsequent copolymerisation. This latter approach, also known as "grafting through", is often not referred to as a divergent approach as the peptide sequence has already been 90 defined prior to incorporation along the polymer backbone. ${ }^{86}$

Figure 3. Rheology data for $\mathrm{mPEO}_{7}-\mathrm{PhePhePhePhe}$ a)
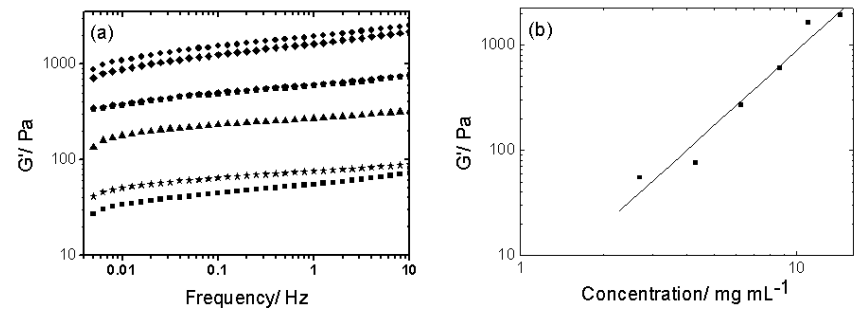

Frequency sweep data for different concentrations of fresh solutions of $\mathrm{mPEO}_{7}$-PhePhePhePhe-OEt in water after dialysis; $2.7 \mathrm{mg} \mathrm{mL}{ }^{-1}(\boldsymbol{\square}) ; 4.3 \mathrm{mg} \mathrm{mL}^{-1}(\star) ; 6.3 \mathrm{mg} \mathrm{mL}^{-1}(\boldsymbol{\Delta}) ; 8.7 \mathrm{mg}$ ${ }_{95} \mathrm{~mL}^{-1}(\bullet) ; 11.0 \mathrm{mg} \mathrm{mL}^{-1}(\diamond)$ and $14.4 \mathrm{mg} \mathrm{mL}^{-1}(\bullet)$. b) Storage modulus $\left(\mathrm{G}^{\prime}\right)$ against concentration, where the solid line represents a linear fit of the data. Reprinted with permission from Tzokova et al. ${ }^{51}$ Copyright 2009 American Chemical Society.

\subsection{Amino Acid Coupling}

100 Both solution-phase and solid-phase amino acid coupling techniques allow the construction of sequence specific peptides, unlike NCA polymerisation, which affords homopolypeptide blocks. Solution-phase is useful for short peptide blocks containing less than ten amino acid residues. ${ }^{90}$ 105 Appropriately protected amino acids are dissolved in an 
organic solvent and reacted together at their respective $N$ - and $C$-termini. Activation of the $C$-terminus is usually required and can be achieved by a number of means. ${ }^{91}$ Judicious choice of protecting groups means that either the $\mathrm{N}$ - or $\mathrm{C}$-terminus 5 can then be deprotected for further reaction.

Solid-phase amino acid coupling (also known as solidphase peptide synthesis, SPPS) was first introduced by Merrifield $^{92}$ in 1963 and is most efficient for producing short to medium peptides (up to 50 residues ${ }^{86}$ ). The $C$-terminus end 10 of the peptide chain is anchored to a solid support resin, which leaves the $N$-terminus end free to react with the free $C$ terminus of an $\mathrm{N}$-terminus protected amino acid in solution (in excess). Following removal of the protecting group on the $N$ terminus of the resin-based peptide, the next solution-based 15 peptide can be introduced or, alternatively, the peptide sequence can be cleaved from the solid resin, which is filtered off to afford the final product in extremely high yield. Each step is quasi-quantitative, but cumulative steps result in lower final yields. Consequently, one should turn to protein 20 expression to create sequence-specific peptide chains comprising greater than 50 amino acid residues.

\subsection{Divergent Peptide Incorporation}

There are three significant divergent approaches for creating peptide-amphiphiles or polymer-peptide conjugates; (i) 25 peptide construction from a polymer (or hydrocarbon for PAs) substrate, (ii) polymerisation from a peptidic initiator and (iii) copolymerisation incorporating a peptide macromonomer.

Peptide construction from a polymer substrate. Amino acid coupling can be carried out on commercially available PEO30 loaded resins. These supports contain chain-end functionalised PEO and are used in the same manner as SPPS, with the exception that, following cleavage from the resin, the final product contains a PEO block. ${ }^{93,94}$ Although this approach produces well-defined polymer-peptide conjugates with 35 simple purification strategies, pre-loaded resins are only currently available with PEO anchored to the surface and the range of available molecular weights is limited. This is where we must turn to different approaches to afford hybrid peptide conjugates with a wider variety of molecular weight, chemical 40 composition and molecular structure. ${ }^{95}$

Stupp's group ${ }^{96-98}$ have synthesised branched PAs by coupling palmitic acid to the $\varepsilon$-amine on a lysine residue, which was anchored to the solid surface on a resin. The remainder of the amino acid sequence was then constructed 45 using selective orthogonal protecting groups. Behanna et al. ${ }^{99}$ also used SPPS to synthesise reverse PAs where the peptide construction was carried out after introduction of the hydrophobic component, using standard Fmoc coupling on a Rink resin-loaded fatty acid to yield PAs with free $N$-termini.

50 Polymerisation from a peptidic initiator. There are a vast number of examples in the literature where peptides (and indeed proteins) have been modified to carry an appropriate functional group to initiate (or conduct chain transfer in the case of RAFT) a controlled polymerisation. A wide variety of 55 polymer-peptide constructs are available with this method. However the approach has not been widely employed to fabricate hydrogelators. This is somewhat surprising since the method has been shown to be extremely effective for producing well-defined polymer-peptide conjugates. ${ }^{100-104}$ For 60 a comprehensive review on controlled polymerisation from peptidic initiators (up to late 2006), the reader is directed to work by Haddleton and co-workers. ${ }^{85}$ The only work known to us at this time which used this approach to produce polymer-peptide hydrogelators is that of Mei et al. ${ }^{105}$ The 65 authors describe a conventional heterogeneous polymerisation strategy whereby the peptidic initiator was bound to a solidsupport. 2-Hydroxyethyl methacrylate was polymerised from a Wang resin support via ATRP and the conjugate was subsequently cleaved from the resin using trifluoroacetic acid.

70 Copolymerisation incorporating a peptide macromonomer. Peptide macromonomers have been used to produce chemically crosslinked hydrogels by a number of groups, with selected examples of the work by Bencherif, ${ }^{106} \mathrm{Hu}^{107}$ and Zimmermann. ${ }^{108}$ However, there is currently only one 75 example in the literature where a peptide macromonomer was designed to form polymer-peptide constructs which selfassembled to form hydrogels. Wu et al. ${ }^{109}$ reacted the $N$ terminus of an amino acid sequence with a methacryloylbased carboxylic acid and subsequently copolymerised the 80 peptide macromonomer with $\operatorname{poly}(N$-(2-hydroxypropyl) methacrylamide). Although this approach is somewhat elegant, the reported yields of the peptide macromonomer synthesis were $5-15 \%$. Ayres et al. ${ }^{110}$ did indeed report the self-aggregation of an elastin-like polymer-peptide construct, 85 however there was no discussion regarding hydrogelation of these materials. A very recent example of a polymer-peptide copolymer (synthesised from an oligolysine macromonomer), which was shown to form gels at specific concentrations during polymerisation has been highlighted. The authors of 90 this work, however, wished to avoid the presence of gel and so employed conditions to ensure that the material remained in solution. ${ }^{111}$

\subsection{Convergent Peptide Incorporation}

The most common method for producing peptide conjugates is 95 a convergent approach because the building block materials are often incompatible with one another. Convergent strategies involve the parallel syntheses of both polymer and peptide constructs followed by a coupling step, Figure 4 .

The coupling step employed relies on the success of chemical 100 ligation; reactions derived from small molecule organic chemistry. Difficulties arise when employing such reactions with macromolecules, due to the significantly lower concentration of functional groups and the potential steric barriers at reaction sites. ${ }^{113}$ To improve yields, highly efficient 105 coupling reactions are sought in combination with excess reagent equivalents. The most common coupling reactions used involve "click" reactions, ${ }^{114,115}$ such as maleimide-thiol conjugation $^{116,} 117$ and copper(I)-catalysed azide-alkyne cycloadditions. ${ }^{118,119}$ For example, Yang et al. ${ }^{52,120}$ used free 110 radical polymerisation to polymerise statistical copolymers of poly( $N$-(2-hydroxypropyl)methacrylamide-co- $N$-(3-

aminopropyl) methacrylamide), as shown in Figure $4 \mathrm{a}$. The primary amine groups were then reacted to afford a polymer backbone with pendant maleimide groups. These groups were 
then clicked to thiol-terminated amino acid sequences. Final yields of $40-60 \%$ were reported. Jing et al. ${ }^{53}$ also used this coupling reaction to afford polymer-peptide hydrogelators. However, this time, triblock copolymers were afforded with 5 varying success $(24-41 \%$ yields) by reacting bismaleimideterminated PEO with a cysteine-terminated peptide (Figure 4b). Tzokova et al. ${ }^{51}$ used azide-alkyne coupling to produce a low molecular weight hydrogelator where a short PEO chain was coupled to tetraphenylalanine $\left(\mathrm{PEO}_{7}-\mathrm{PhePhePhePhe}\right)$, 10 Figure 4d. Monohydroxy $\mathrm{PEO}_{7}$ was converted to $\mathrm{PEO}_{7}-\mathrm{N}_{3}$ and subsequently reacted with an alkyne-modified PhePhePhePhe moiety (synthesised by solution phase amino acid coupling) with $73 \%$ click efficiency. Pegylation, the coupling of PEO to peptides or proteins, is a well-studied field (due to the 15 biocompatibility of $\mathrm{PEO}$ and its effect in prolonging the lifetime of biological compounds in the body) and is reviewed in detail elsewhere. ${ }^{121}$

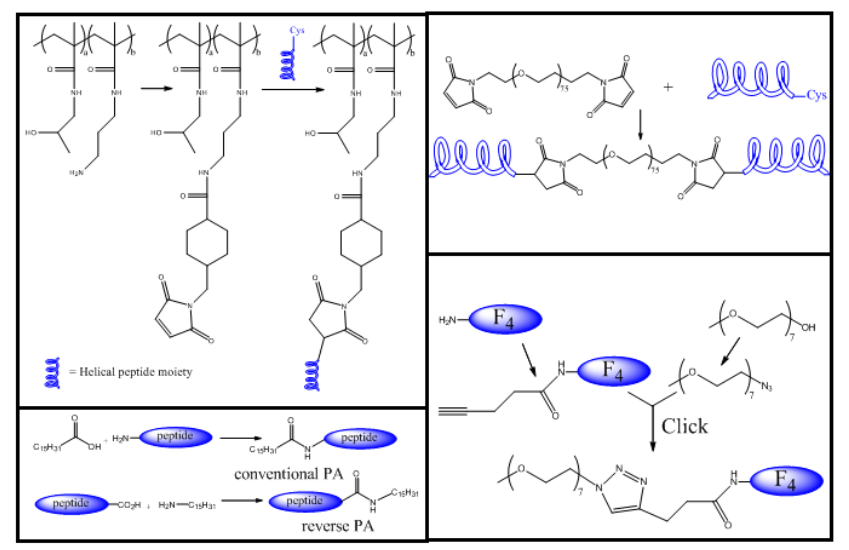

Figure 4. Selected convergent approaches for the synthesis of peptide conjugates; A) HPMA-peptide graft copolymers, ${ }^{52} \mathrm{~B}$ ) 20 peptide-PEO-peptide triblock copolymers, ${ }^{53}$ C) peptide amphiphiles $^{23,112}$ and D) PEO-tetraphenylalanine (PhePhePhePhe, $\left.\mathrm{F}_{4}\right){ }^{51}$

For PA synthesis, alkylation is generally achieved by standard 25 amidation following peptide construction. The hydrophobic aliphatic chain can be a fatty acid (typically palmitic acid), which reacts with the amine of the $\mathrm{N}$-terminus of the peptidic molecule ${ }^{23,} 99, \quad 122-127$ to produce conventional peptide amphiphiles or an alkylamine which reacts with the carboxylic

30 acid at the $C$-terminus ${ }^{112}$ to yield "reverse" PAs (see Figure $4 \mathrm{c}$ and section 4.2).

\section{Peptide Conjugate Hydrogelators}

Here, we review the three main classes of peptide-conjugates that have been shown to be efficient hydrogelators.

\section{4.1. Peptides Conjugated to Aromatic Groups}

There has recently been considerable work carried out on the use of functionalised-dipeptides as hydrogelators. Dipeptides are clearly of interest from a commercial point of view, being significantly cheaper than longer oligopeptides. Certain 40 unfunctionalised dipeptides have been shown to form hydrogels. For example, de Groot et al. showed that isovaline- phenylalanine $^{128}$ forms gels at $1.5 \mathrm{wt} \%$ at $\mathrm{pH}$ 5.8. Assembly occurred here by specific ionic interactions between $N$ and $C$ termini of the peptide. Interestingly, a slightly less hydrophobic 45 dipeptide (valine-phenylalanine) failed to yield hydrogels. The assembly of an aqueous solution of $\alpha, \beta$-dehydrophenylalanine into hydrogels has also been reported at a concentration as low as 0.2 wt $\%$ in a buffer solution. ${ }^{129}$ Diphenylalanine has been shown to assemble into nanotubes or nanowires ${ }^{130-132}$ depending on the 50 conditions of assembly. This implies that the assembly into fibres observed with $\alpha, \beta$-dehydrophenylalanine leading to hydrogelation arises from the conformational differences compared to the ${ }_{\mathrm{L}, \mathrm{L}}$-dipeptide. These are rare examples, however. A number of other dipeptides have been shown to crystallise in 55 aqueous solutions. ${ }^{133}$

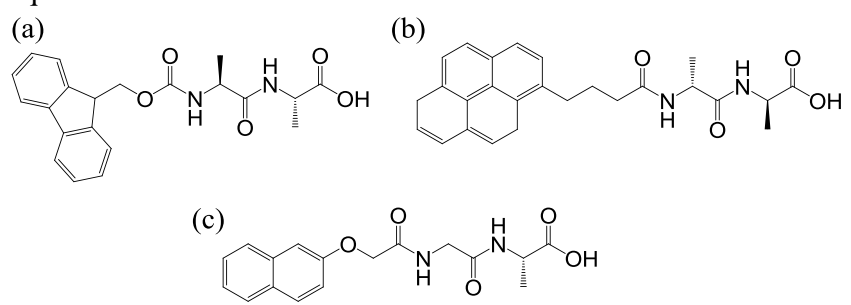

Figure 5. Structures of example $N$-functionalised dipeptide gelators. (a) Fmoc $_{-}{ }_{\mathrm{L}}-\mathrm{Ala}_{-}-\mathrm{Ala}^{134}$ (b) Pyrene-dipeptide ${ }^{135}$ (c) Naphthalene-dipeptide. ${ }^{136}$

60

On the other hand, a large number of reports now demonstrate that dipeptides conjugated to a hydrophobic, $\pi$-stacking group can act as efficient hydrogelators. Suitable functional groups include naphthalene, substituted naphthalenes, Fmoc and 65 pyrene, Figure 5.

\subsubsection{Fmoc-Dipeptides}

The first examples of such gelators were dipeptides conjugated to Fmoc groups, a common protecting group used during peptide 70 synthesis. Vegners et al. ${ }^{137}$ first demonstrated that hydrogels could be prepared using Fmoc-Leu-Asp, Fmoc-Ala-Asp or FmocIle-Asp by the cooling of an aqueous solution at $0.5 \mathrm{wt} \%$ (the more hydrophilic Fmoc-Ala-Asp formed gels at a concentration of $6.7 \mathrm{wt} \%$ ). Later, Zhang et al. ${ }^{134}$ found that a number of Fmoc75 dipeptides could form hydrogels when the solution of a Fmocdipeptide at high $\mathrm{pH}$ was lowered to approximately $\mathrm{pH} 3$. A number of dipeptides were examined including Fmoc-AlaAla, Fmoc-GlyGly, Fmoc-GlyAla, Fmoc-GlySer and Fmoc-GlyThr, with the more hydrophilic dipeptides again requiring significantly 80 higher concentrations to form hydrogels (e.g. Fmoc-AlaAla formed gels at a concentration of $3.9 \mathrm{mM}$, whereas the more hydrophilic Fmoc-GlySer formed gels at $52 \mathrm{mM}$ ). These hydrogels were also found to be temperature sensitive. Interestingly, exposing Fmoc $_{-}{ }^{-}-\mathrm{Ala}^{-}{ }^{-}$-Ala to vancomycin (known 85 to have a strong ligand-receptor interaction with ${ }^{-}$-Ala- $\left.{ }^{-}-\mathrm{Ala}\right)$, resulted in a gel-to-sol transition. On the other hand, vancomycin had no effect on the gel formed by Fmoc $_{-}{ }_{\mathrm{L}}-\mathrm{Ala}_{-} \mathrm{L}_{\mathrm{L}}-\mathrm{Ala}$, emphasising the importance of the exact position of the amino acid functional groups. A number of reports regarding the use of 90 Fmoc-dipeptides as hydrogelators have now appeared. ${ }^{71,82,138-143}$ It is now known that a wide variety of Fmoc-dipeptides can form 
hydrogels under the appropriate conditions. Perhaps the most widely studied of these is Fmoc-diphenylalanine (Fmoc-PhePhe), which was first reported as an efficient gelator in $2006 .{ }^{82,138}$ The interest in this gelator arises from the fact that hydrogels can be 5 prepared at physiological $\mathrm{pH}$, vital for biomedical applications.

Assembly of Fmoc-PhePhe has been carried out in different ways. The dipeptide can be dissolved in a solvent such as dimethylsulfoxide (DMSO) or hexafluoroisopropanol (HFIP) at relatively high concentrations $(100 \mathrm{mg} / \mathrm{mL}) .{ }^{82,139,140}$ Dilution of 10 such a stock solution with water or buffer results in the formation of a network of fibres leading to transparent hydrogels at typical concentrations of $5 \mathrm{mg} / \mathrm{mL}(0.5 \mathrm{wt} \%)$. Noticeably, one report indicates a lower stability in buffer as compared to deionised water, in addition to the impact of concentration of the peptide 15 solution on gel stability. ${ }^{139}$ Dilution of a $100 \mathrm{mg} / \mathrm{mL}$ solution to $0.5 \mathrm{wt} \%$ resulted in an unstable gel whereas dilution of a 25 $\mathrm{mg} / \mathrm{mL}$ solution to the same final concentration resulted in a stable gel. The rheology of a hydrogel formed from FmocPhePhe in water exhibits $\mathrm{G}^{\prime}>\mathrm{G}^{\prime \prime}$ as expected for a hydrogel, with ${ }_{20} \mathrm{G}^{\prime}$ being of the order of $10^{4} \mathrm{~Pa}^{82}$ As expected, the gel strength was affected by the peptide concentration. IR spectroscopy of the gel showed peaks at 1607,1658 and $1691 \mathrm{~cm}^{-1}$, consistent with the presence of $\beta$-sheets and $\beta$-turns. ${ }^{82}$ Subsequent results from the same authors showed a major peak at $1653 \mathrm{~cm}^{-1}$ and a minor 25 peak at $1690 \mathrm{~cm}^{-1}$ again assigned to a $\beta$-sheet conformation. ${ }^{140}$ An alternative method of assembly has been reported by Ulijn et $a l .{ }^{138}$ Here, solutions of the dipeptide above $\mathrm{pH} 8$ were prepared. Addition of concentrated $\mathrm{HCl}$ to re-adjust the $\mathrm{pH}$ resulted in the formation of a self-supporting gel at $\mathrm{pH}<8$. Clearly, care must 30 be taken with this method, since the Fmoc group is sensitive at basic conditions. ${ }^{144}$ Here again, a fibrous network was observed by SEM which led to the formation of a hydrogel. Rheology showed that such gels had a $\mathrm{G}^{\prime}$ which varied from $1900 \mathrm{~Pa},{ }^{143}$ to $10,000 \mathrm{~Pa}^{142}$ to $21,000 \mathrm{~Pa}^{141}$ depending on the report. IR 35 spectroscopy of these gels revealed a strong peak at approximately $1630 \mathrm{~cm}^{-1}$ and a medium intensity peak at 1690 $\mathrm{cm}^{-1}$, indicative of the formation of anti-parallel $\beta$-sheets. ${ }^{141}$ The formation of $\beta$-sheets was also shown by circular dichroism, ${ }^{142}$ where a minimum at $218 \mathrm{~nm}$ was observed. In this work, the 40 assembly of primary fibres into tapes was observed, and a model structure generated from the data suggested that Fmoc-PhePhe assembles into cylindrical structures due to the formation of antiparallel $\beta$-sheets and anti-parallel $\pi$-stacked fluorenyl groups, Figure 6.

45 Interestingly, later work showed that the reason for assembly at physiological $\mathrm{pH}$ was the surprisingly high apparent $\mathrm{p} K_{\mathrm{a}}$ of the $C$-terminus of the dipeptide. ${ }^{145}$ Titration with $\mathrm{HCl}$ revealed this value to be approximately 9.9 with a second apparent $\mathrm{p} K_{\mathrm{a}}$ found at approximately 5.8. These apparent $\mathrm{p} K_{\mathrm{a}}$ values were related to 50 two different structural transitions resulting from the selfassembly process. Titrating to different $\mathrm{pH}$ values resulted in significantly different IR spectra to that found on gelation at $\mathrm{pH}$ 7 , with two strong peaks at 1625 and $1687 \mathrm{~cm}^{-1}$ found at both $\mathrm{pH}$ 9.1 and 6.8. Whilst the positions are still reminiscent of the 55 formation of anti-parallel $\beta$-sheets, the intensity of the peak at $1687 \mathrm{~cm}^{-1}$ was surprisingly strong and differed from that reported previously. ${ }^{141}$ Similarly, the rheology for a slowly titrated system shows significantly lower values of $\mathrm{G}^{\prime}\left(1 \mathrm{~Pa}\right.$ compared to $\left.10^{4} \mathrm{~Pa}\right)$. It is known for a number of different systems that the kinetics of ${ }_{0}$ hydrogelation strongly affects the outcome of the process. ${ }^{35,71,146 \text {, }}$

${ }^{147}$ In all cases, lowering the $\mathrm{pH}$ past the second apparent $\mathrm{p} K_{\mathrm{a}}$ results in precipitation, with TEM showing large flat ribbons at lower $\mathrm{pH}$ where a gel is no longer present. IR spectroscopy demonstrates that the $\beta$-sheets were broken up with evidence of 65 random coils appearing at low $\mathrm{pH}$.
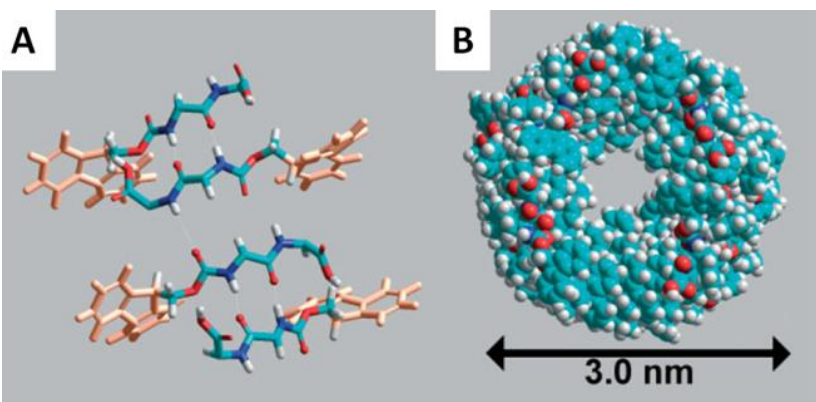

Figure 6. A model structure of Fmoc-PhePhe peptides in an antiparallel $\beta$-sheet arrangement. (a) $\pi$-stacking occurs between Fmoc 70 groups from alternate $\beta$-sheets. (b) To maintain the interactions between the fluorenyl groups and allow the twist of the $\beta$-sheets, a cylindrical structure is formed. Adapted from Smith et al. ${ }^{142}$ Reproduced by permission from Wiley-VCH.

75 To date, these Fmoc-PhePhe hydrogels have been utilised in two applications, encapsulation and cell culturing. The gels could be used to control the release of drugs; fluorescein was shown to diffuse through the gels with a diffusion coefficient of $3.61 \times 10^{-}$ ${ }^{10} \mathrm{~m}^{2} \mathrm{~s}^{-1}$, whereas the larger fluorescein-labelled insulin was 80 retained in the gel. ${ }^{82}$ Recent results have shown that the mesh size decreases with dipeptide concentration in these gels, with the free space between the fibrils being of the order of $12 \mathrm{~nm}$ at a concentration of $4 \mathrm{mg} / \mathrm{mL}$. ${ }^{83}$ Additionally, Chinese hamster ovary cells were found to be viable when suspended about the gel. ${ }^{82,140}$ ${ }_{85}$ Liebmann et al. ${ }^{139}$ demonstrated that the addition of a peptide solution in DMSO to a cell-containing PBS buffer solution resulted in the formation of a gel containing the cells. Diffusion of dyes within the gels was again demonstrated, Figure 7. Cell growth within hydrogels prepared from Fmoc-PhePhe as well as 90 those prepared from mixtures of Fmoc-PhePhe and Fmoc-amino acids has also been demonstrated by Ulijn's group. ${ }^{138,141,143}$

As noted above, a range of other Fmoc-dipeptides are also efficient hydrogelators. When assembled by a $\mathrm{pH}$ trigger, these require a lower $\mathrm{pH}$ than Fmoc-PhePhe. However, it has been 95 shown that Fmoc-PheGly still forms a hydrogel when a solution in DMSO is diluted with ultrapure water. ${ }^{140}$ Recently, it has been shown that the hydrolysis of glucono- $\delta$-lactone $(\mathrm{GdL})$ to gluconic acid can be used to induce a $\mathrm{pH}$ change in Fmoc-dipeptide solutions. $^{71}$ This has two main advantages. Firstly, the rate of ${ }_{00} \mathrm{GdL}$ dissolution is far higher than the rate of hydrolysis, meaning that a highly uniform and reproducible gel can be prepared using this technique since mixing is not required during the actual gelation. Secondly, the rate of hydrolysis is sufficiently slow that the process by which assembly occurs can be followed. Using 
this technique, it was demonstrated that the fluorescence spectrum changes immediately, showing the red shift often reported on assembly of Fmoc-dipeptides, implying that $\pi$ stacking is occurring as the first step of the assembly process. The 5 circular dichroism spectra on the other hand showed that the formation of structures giving rise to these signals takes significantly longer. Using microscopy, it was shown that assembly into fibres begins as soon as the $\mathrm{pH}$ starts to drop, with long fibres being formed well in advance of any gel-like 10 properties being measureable by rheology in agreement with the spectroscopic data. Using this method, very stiff gels with a $\mathrm{G}^{\prime}$ of up to $184,000 \mathrm{~Pa}$ could be reproducibly prepared at concentrations of $3 \mathrm{mg} / \mathrm{mL}$. Recent results show that, at a concentration of $14.6 \mathrm{mM}$, the hydrophobicity of the Fmoc15 dipeptides determines whether a gel will form at $\mathrm{pH} 4 .{ }^{148}$ Fmocdipeptides with a $\log \mathrm{P}$ (a measure of the hydrophobicity) lower than 2.4 form gels that synerise, those with a $\log \mathrm{P}$ between 2.4 and 5.5 form stable gels and Fmoc-PhePhe $(\log P=5.6)$ does not form a gel at this $\mathrm{pH}$, in agreement with other results. ${ }^{145}$

20

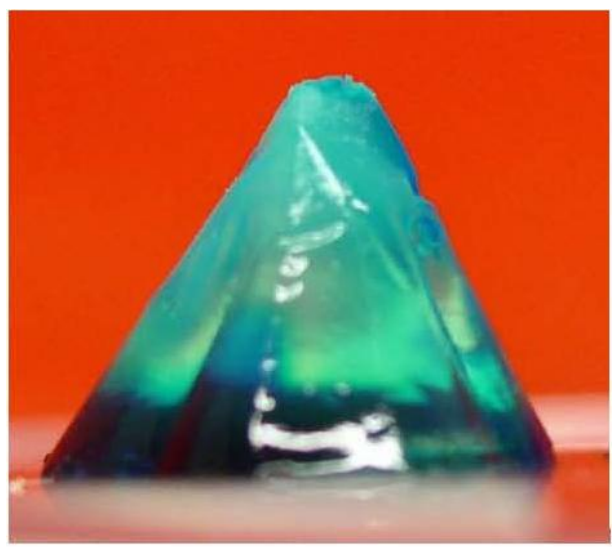

Figure 7. Dye diffusion through a Fmoc-PhePhe hydrogel achieved by applying a green stain to the bottom a moulded gel. The height of the sample is approximately $20 \mathrm{~mm} .{ }^{139}$

25

A number of recent reports from the Ulijn group have demonstrated that gelation can also be induced and controlled by enzymatic-triggered assembly. Enzymatic-triggered assembly has also been demonstrated for Fmoc-amino acids. ${ }^{149-151}$ In the first 30 example, ${ }^{152}$ thermolysin was used to couple a dipeptide to a Fmoc-amino acid. Fmoc-tripeptides were formed in varying yields, with gels being formed on yields of as little as $16 \mathrm{wt} \%$ tripeptide (corresponding to approximately $4 \mathrm{mg} / \mathrm{mL}$ ). Gelation was tested by vial inversion. Further work extended this to Fmoc35 dipeptide methyl esters, which were able to form a hydrogel when threonine was used as the first amino acid in the sequence. ${ }^{153}$ It was also demonstrated that Subtilisin, an enzyme used for ester hydrolysis, could be used to convert a sol of an Fmoc-dipeptide methyl ester to an Fmoc-dipeptide at $55{ }^{\circ} \mathrm{C}$. On 40 cooling, hydrogels were formed. High yields of de-esterification were achieved. It was later demonstrated that enzyme-triggered assembly allows localised nucleation and growth with fibres being aggregated around the enzyme at early time points (Figure 8). ${ }^{154}$ The complexity of the thermolysin system has been
45 described, showing that the outcome of the process depends on the composition of precursors in the system, with a dynamic combinatorial approach being taken. ${ }^{155}$

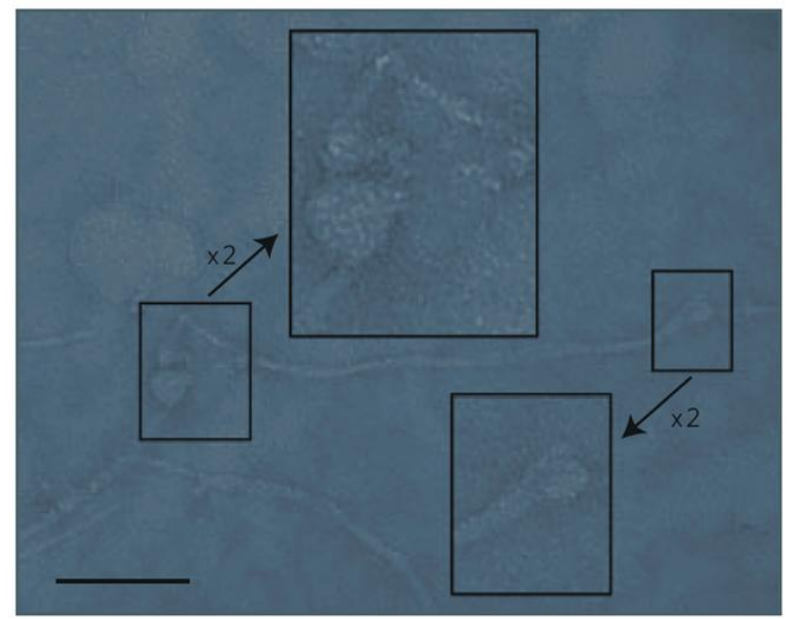

Figure 8. TEM image demonstrating spatial confinement of 50 nucleation and growth. Fibres are observed locally to an enzyme at early time points in the enzyme-assisted assembly of FmocPhePhePhe. Scale bar $=100 \mathrm{~nm}$. Reprinted by permission from Macmillan Publishers Ltd: Nature Nanotechnology, Williams et al. ${ }^{154}$ copyright 2009.

55

Gels can be formed from conjugates with longer peptides attached to a Fmoc unit. ${ }^{156}$ The use of Fmoc-tripeptide gelators has recently been demonstrated which formed gels at low $\mathrm{pH}$ as for the dipeptides and also at high $\mathrm{pH}$ in a borax buffer. ${ }^{157} \mathrm{Ma}$ et $60 \mathrm{al}$. have used Fmoc-pentapeptides to form hydrogels. Again, a pH trigger was used to form the gels, with the $\mathrm{pH}$ at which the gels formed being dependant on the peptide sequence. ${ }^{158}$ Longer peptides can also be used. A Fmoc group was conjugated to a fragment of the transthyretin protein $\left(\mathrm{TTR}_{105}{ }^{-115}\right)$. This fragment ${ }_{65}$ is known to form fibrillar structures akin to amyloid fibres. Cooling a solution of the peptide conjugate slowly from $70{ }^{\circ} \mathrm{C}$ to $40{ }^{\circ} \mathrm{C}$ resulted in the formation of a gel. Whilst the gel properties were not studied, it is interesting to note that in this case, extended $\pi$-stacking was not thought to be present. On the other 70 hand, recent results from $\mathrm{Xu}$ et al. demonstrate that efficient stacking of fluorenyl groups is possible for some Fmocpentapeptides. $^{158}$

\subsubsection{Pyrene-Dipeptides}

75 Whilst significant work has been done regarding Fmocdipeptides, these are by no means the only examples of $\mathrm{N}$ functionalised dipeptide gelators. A pyrene-dipeptide has been reported. ${ }^{135}$ Whilst the gels formed using $\mathrm{D}^{-}$Ala- ${ }^{-}$-Ala as the dipeptide were relatively weak $\left(\mathrm{G}^{\prime}=120 \mathrm{~Pa}\right)$, binding to 80 vancomycin (as described above for Fmoc- ${ }^{-}-\mathrm{Ala}^{-}{ }^{-}-\mathrm{Ala}$ ) resulted in a large increase in the gel stiffness $\left(\mathrm{G}^{\prime}=160,000 \mathrm{~Pa}\right)$. Moreover, the use of the ${ }_{\mathrm{L}}-\mathrm{Ala}_{-}-\mathrm{Ala}$ dipeptide resulted in a comparatively low ten-fold increase in $\mathrm{G}^{\prime}$ over the gelator alone.

\section{${ }_{85}$ 4.1.3. Naphthalene-Dipeptides}


A significant amount of work has also been carried out with naphthalene-dipeptides. As with the Fmoc-dipeptides and pyrenedipeptides, the naphthalene rings are thought to provide $\pi$ stacking interactions that help induce one-dimensional assembly 5 and hence fibre formation. Xu's group have reported a number of hydrogels utilising naphthalene-dipeptides. Hydrogels were successfully prepared from a subset of a library of naphthalenedipeptides. ${ }^{136}$ Those that formed gels did so at a peptide conjugate concentration of around $1 \mathrm{mg} / \mathrm{mL}$ at approximately $\mathrm{pH}$ 104 . As for their other hydrogels prepared from low molecular weight gelators, the gels were found to exhibit a gel-to-sol transition at increased temperature $\left(45-52{ }^{\circ} \mathrm{C}\right.$ in these cases). Interestingly, the naphthalene-dipeptides that successfully formed gels had an $\mathrm{OCH}_{2}$ linker between peptide and naphthalene ring 15 (see Figure 5c). Conversely, a $\mathrm{CH}_{2}$ linker resulted in precipitation. This was attributed to the $\mathrm{OCH}_{2}$ spacer allowing the necessary conformations to be adopted, with a simple model demonstrating that this linker allowed planarity to be achieved. As for gels prepared from Fmoc-dipeptides, ${ }^{71}$ a weak frequency 20 dependence was observed by rheology with $\mathrm{G}^{\prime}>\mathrm{G}^{\prime \prime}$ as expected for a hydrogel. In these cases, helical fibres were formed, with the helicity being opposite when $\mathrm{L}^{-}$or $\mathrm{D}^{-}$peptides were used, respectively. As for the Fmoc-dipeptides discussed above, these hydrogels were found to be biocompatible as confirmed by an 25 MTT assay using HeLa cells.

Further work has focused on the use of naphthalene-dipeptides where $\beta$-amino acids were coupled to a naphthalene ring. ${ }^{159}$ Oligopeptides that are formed from the naturally occurring $\mathrm{L}^{-}$ amino acids are known to be biodegradable by proteolysis, which 30 can result in a shortening of the in vivo lifetimes. ${ }^{160,161}$ Hence, the $\beta$-amino acids are used to confer proteolytic resistance to hydrogels. As for the gelators prepared from $\mathrm{D}^{-}$or $\mathrm{L}^{\text {-amino acids, }}$ the naphthalene- $\beta$-Phe- $\beta$-Phe dipeptide formed gels at concentrations of $5 \mathrm{mg} / \mathrm{mL}$ and $\mathrm{pH} 6.2$. Interestingly, the less 35 hydrophobic naphthalene-Gly-Ala formed gels at $\mathrm{pH}$ 4.3, possibly due to a change in $\mathrm{p} K_{\mathrm{a}}$ of the terminal carboxylic acid as described above for the Fmoc-dipeptide series. Also, these dipeptides were not linked to the naphthalene ring by an $\mathrm{OCH}_{2}$ spacer, which was mooted above as being important. A gel-to-sol 40 transition at $45-48{ }^{\circ} \mathrm{C}$ (depending on the sequence) was observed. The gels formed from these dipeptides had $\mathrm{G}^{\prime}$ of $100-$ $200 \mathrm{~Pa}$, significantly lower than found for other naphthalenedipeptides and Fmoc-dipeptides (see above).

Further work with the naphthalene- $\beta$-Phe- $\beta$-Phe hydrogels 45 used radioactive tracers to examine the controlled release from these systems. ${ }^{162}$ An MTT assay with HeLa cells was used to assess biocompatibility and the gels were found to have an $\mathrm{IC}_{50}$ (the half maximal inhibitory concentration i.e. the concentration needed to inhibit cell growth by $50 \%$ ) higher than $500 \mu \mathrm{M}$. Also, 50 as expected from the use of $\beta$-amino acids, the gels were found to resist enzymatic degradation with proteinase $\mathrm{K}$ (for comparison,

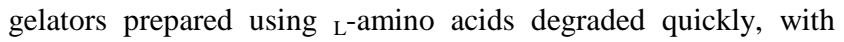
only $37 \%$ remaining after $24 \mathrm{~h}$ ). Additionally, no clinical, haematological or biochemical toxicity was observed when 55 subcutaneous injection of the gels was carried out under the middorsal skin of rats with no obvious inflammation observed after 42 days. Controlled release was imaged via single photon emission computed tomography and showed that the release of epideride from the gel occurred over a few hours and was slower 60 than when simply injecting drug solution.
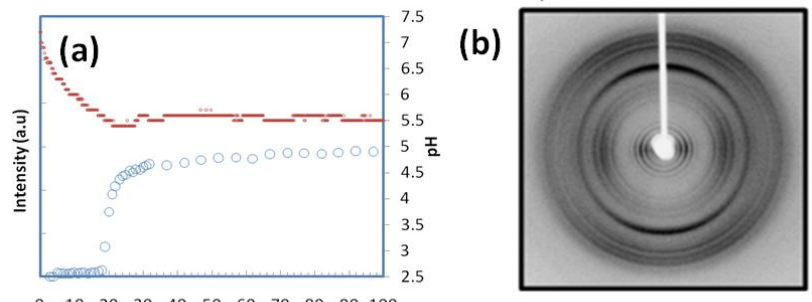

Time/min

Figure 9. (a) Normalised change in ThT fluorescence at $485 \mathrm{~nm}$ $\left(\lambda_{\mathrm{ex}}=455 \mathrm{~nm}\right)$ on addition of solutions of dipeptide derivative to GdL (blue data). Overlaid is the change in $\mathrm{pH}$ with time (red ${ }_{65}$ data). (b) X-ray fibre diffraction patterns collected from in situ prepared fiber alignments from gel at a final $\mathrm{pH}$ of 5.0. The fibre axis is vertical to the diffraction pattern. The major meridional reflection was found to be at $4.5 \AA$, arising from the $\beta$-strand spacing along the fibre axis. Reprinted with permission from ${ }_{70}$ Chen et al. ${ }^{163}$ Copyright 2010 American Chemical Society.

Recently, the assembly of a brominated naphthalene-dipeptide to form a hydrogel was studied in detail. ${ }^{163}$ Utilising GdL to alter the $\mathrm{pH}$ allowed the rate of assembly to be controlled. Assembly 75 was shown to start as the $\mathrm{p} K_{\mathrm{a}}$ of the dipeptide was reached. As for Fmoc-PhePhe discussed above, the apparent $\mathrm{p} K_{\mathrm{a}}$ was found to be higher than expected for the $C$-terminus of a peptide (approximately 5.4). As the $\mathrm{pH}$ was decreased, the formation of $\beta$-sheets was demonstrated by IR and X-ray fibre diffraction, ${ }_{80}$ Figure 9. The rate of assembly was shown to have an effect on the ability of the gels to withstand strain, although the absolute values of $\mathrm{G}^{\prime}$ were found to be independent of the rate of assembly. Assembly was also shown to proceed via a two-stage process by the incorporation of thioflavin $\mathrm{T}$ (ThT, a stain 85 typically used for amyloid proteins).

In addition to $\mathrm{pH}$-triggered gelation, hydrogels have been prepared from naphthalene- $\beta$-Phe- $\beta$-Phe- $\alpha$-Tyrphosphatase using an enzyme to cleave the phosphate from the terminal amino acid. ${ }^{146}$ The tripeptide forms gels at $0.5 \mathrm{wt} \%$ and a $\mathrm{pH}$ of 1.5 , but 90 above this $\mathrm{pH}$, no gel is formed. However, using an acid phosphatase to cleave the phosphate causes gel formation at $\mathrm{pH}$ 4.8. Gels were also found to form in the presence of blood. The kinetics of gelation depended on the concentration of the enzyme used, which was found to link directly to the mechanical

${ }_{95}$ properties of the gels. $\mathrm{G}^{\prime}$ for the gels was found to be higher the quicker the gel was formed (i.e. the higher the amount of enzyme used, the higher the storage modulus, reaching a maximum $\mathrm{G}^{\prime}$ of $4000 \mathrm{~Pa}$ ). In addition, the fibre uniformity decreased as the rate of gelation increased. This clearly shows that the speed of gelation 100 affects both the morphology of the nanofibres and the mechanical properties of the final gel. This presumably correlates with the observations regarding sample uniformity and $\mathrm{G}^{\prime}$ values in the discussion regarding the Fmoc-dipeptides above.

\subsection{Peptide-amphiphiles}


Although there are many examples of amphiphilic peptidebased molecules, the term "peptide-amphiphile" (PA) is generally used for molecules with a hydrophilic peptidic segment covalently attached to a linear alkyl chain (see Figure 5 10). Conventionally, the alkyl chain is attached to the $N$ terminus of the peptidic moiety leaving a free terminal carboxylic acid on the peptide. Reverse PAs, on the other hand, have a free terminal amine group as the hydrocarbon chain is attached to the $C$-terminus. Other systems, which are 10 not covered in this review, include amphiphilic amino acid sequences (where the hydrophobic and hydrophilic character is provided by the residues themselves) and block copolypeptides. For a tutorial review covering these different peptidic amphiphiles, the reader is directed elsewhere. ${ }^{164}$

15 PAs benefit from the self-assembly behaviour of conventional amphiphiles (in aqueous media the hydrophobic segments bury themselves to reduce their unfavourable interactions with the surrounding hydrophilic environment ${ }^{165}$ ) to form cylindrical micellar nanofibres. These materials will 20 form viscoelastic three-dimensional hydrogels when the concentration is sufficiently high to cause intermolecular entanglement of the fibres. More importantly, however, unlike with conventional block copolymer amphiphiles, the incorporation of the peptide sequence allows considerable 25 control over the self-assembly process and the final physical, chemical and biological properties of the hydrogels. The biocompatible peptide segment has an adaptable composition (chain length, charge and sequence), which can be drastically altered or finely-tuned to suit the target application.

30 PA hydrogels were first designed to direct mineralisation of calcium hydroxyapatite (the inorganic constituent of assemblies in bones and teeth). ${ }^{23}$ The specific self-assembling behaviour of the PA provided the perfect scaffold for crystallisation of the mineral, as crystal growth was directed 35 along the axes of the nanofibres. Moreover, the morphology of the final material somewhat mimicked that observed between collagen and calcium hydroxyapatite in bones. In this first example, however, the PA had a more complicated primary structure than many of its successors. The peptidic 40 segment of the molecule consisted of four major parts; i) a reversibly crosslinkable peptide segment comprising of cysteine residues, ii) a flexible triglycine linker, iii) an apatite crystallisation-directing group (phosphorylated serine) and iv) the commonly used bioactive epitope, RGD. More recently, ${ }_{45}$ Paramonov et al. ${ }^{123}$ carried out a systematic study on $26 \mathrm{PAs}$ to identify to essential design rules for effective self-assembly into bioactive nanofibrous hydrogels. The authors found that there were only three vital segments of the PA required; i) a hydrophobic aliphatic tail (the precise length needed depends 50 on the peptidic head group ${ }^{125}$ ), ii) a critical four amino acid sequence with $\beta$-sheet forming propensity to direct hydrogen bonding along the axis of the nanofibres and iii) a peripheral peptide region for bioactivity. Control of the $\beta$-sheet forming section was shown to have the most influence on the final 55 morphology, with the absence of $\beta$-sheet formers giving rise to spherical nanostructures in place of nanofibres with high persistence lengths. The amino acid residues on the periphery of the PA were shown to have little effect on the morphology; this segment can therefore be used to insert some kind of ${ }_{60}$ "code" of (bio)activity depending on the target application required. Obviously, other units can be incorporated into the structure for varying applications, but these constitute the ground rules for all PA nanofibre design parameters.

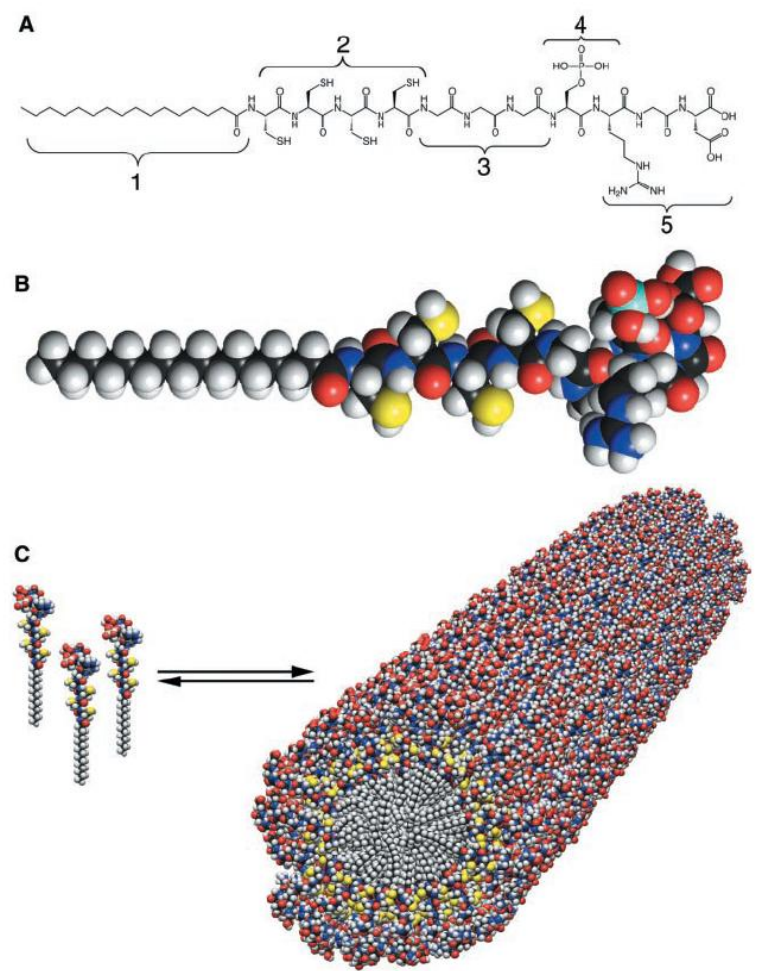

Figure 10. (A) Chemical structure of the peptide amphiphile, ${ }_{65}$ highlighting five key structural features. Region 1 is a long alkyl tail that conveys hydrophobic character. Regions 2-5 are different peptidic domains important for cross-linking, flexibility, interaction with calcium and cell adhesion, respectively. (B) Molecular model of the PA showing the overall conical shape of 70 the molecule going from the narrow hydrophobic tail to the bulkier peptide region. (C) Self-assembly of PA molecules leads to a cylindrical micelle. From Hartergink et al. ${ }^{23}$ Reprinted with permission from AAAS.

75 Since this pioneering work, PA gels have been used as in vivo angiogenic (growth of new blood vessels from existing ones) materials, ${ }^{166}$ hybrid bone implants, ${ }^{96}$ scaffolds for cell adhesion, ${ }^{167}$ dental stem cells ${ }^{168}$ and rat neurons ${ }^{169}$ and for the differentiation of human bone marrow cells. ${ }^{170}$ One of the 80 major advantages of PAs is their versatility in molecular design. For example, a variety of functional groups can be incorporated into the construct to produce materials which only gel in the presence of a specific trigger. This is particularly useful in the field of biomedicine, where changes 85 in physiological conditions or external stimuli can be used to create biomimetic scaffolds in vivo. Such triggers include light, ${ }^{171,}{ }^{172}$ heparin, ${ }^{173}$ calcium, ${ }^{174}$ cis-platin ${ }^{175}$ and counter ion screening. ${ }^{176}$

In contrast to the Fmoc-peptide derivatives discussed in 90 section 4.1, PAs have not been used extensively to create particularly strong gels ( $\mathrm{G}^{\prime}$ typically around $200 \mathrm{~Pa}$ or lower, ${ }^{127}$ although there are exceptions ${ }^{77}$ ) and have generally 
been used as biomedical scaffolds. Some work has been undertaken, however, to optimise the strength of PA hydrogels. For example, different aliquots of phospholipids were added to PA samples prior to self-assembly. ${ }^{177}$ The 5 phospholipids were shown to substitute for PA molecules in the nanofibres to create hydrogels of varying strengths depending on the amount of phospholipid added (in this case, $5 \mathrm{~mol} \%$ was revealed as optimum for mechanical strength). This carefully controlled study showed, for the first time, that 10 additives can be used to strengthen PA hydrogels at no detriment to structural conformation. More recently, Anderson et al. ${ }^{127}$ showed that a biologically inert PA could be effectively mixed with a bioactive PA to enhance structural stability of the final hydrogel whilst maintaining the 15 material's biological function. In some cases, the cell-binding PAs were not able to form standing hydrogels without the incorporation of the structural PA additive, demonstrating the value of this approach for cell encapsulation and other tissue engineering applications. A similar strategy was also 20 exemplified by Niece et al. ${ }^{122}$ who combined two oppositely charged PAs and studied their self-assembly behaviour. On their own, the PAs did not form hydrogels due to the electrostatic repulsion between peptidic segments. However, once mixed at concentrations as low as $0.1 \mathrm{mg} / \mathrm{mL}$, the PAs 25 formed gels comprising composite nanofibres. Reverse PAs, where the aliphatic tail is bound to the $C$-terminus of the peptide, can also be used in this way. ${ }^{99,178}$ Mixtures of reverse PAs and conventional PAs were shown to create more thermally stable hydrogels. This was attributed to a more 30 efficient alignment of the $\beta$-sheets due to anti-parallel stacking of the combined PAs. ${ }^{99}$ Gels made from just one type of PA can only align in a parallel fashion and so the interpeptide bonding is not as intimate. PA molecules have also been chemically cross-linked to improve their toughness using 35 pairs of acetylene groups within the hydrocarbon tail. ${ }^{179}$ The acetylene groups align perfectly due to the specific selfassembling of the peptidic segment. Once nanofibres are formed (by physical interactions only), light irradiation can be used to permanently hold the structure together, Figure 11. 40 This approach exploits the specificity of $\beta$-sheet formation of peptides to produce chemically stable nanofibres.

Greenfield et al. ${ }^{77}$ showed that the mechanical properties of the hydrogels can be controlled by altering the aqueous media in which they are placed rather than altering the composition 45 of the PA or incorporating additives. Gelation, stiffness and strain response were found to be different if either $\mathrm{HCl}$ or $\mathrm{CaCl}_{2}$ was used to induce gelation. $\mathrm{CaCl}_{2}$-PA hydrogels were shown to be stronger (due to ionic bridging as compared to hydrogen bonding in $\mathrm{HCl}$ ), however $\mathrm{HCl}-\mathrm{PA}$ gels recovered 50 most of their stiffness following deformation. This elegant approach shows that the PA does not necessarily have to be modified to control the mechanical behaviour of the hydrogel; however, the in vivo application of this strategy will be heavily dependent on the physiological conditions in which 55 the material is placed.

Controlling the kinetics of the gelation process is also vital for in vivo applications of PA hydrogels. This can be done by molecular design; subtly altering the amino acid sequence in the peptide has huge implications on the rates of self60 assembly. A number of PAs have been investigated in this way. ${ }^{124}$ The results suggest fibre formation is nucleated by aggregates that pre-exist the onset of the trigger for gelation. Hence, the more hydrophobic PAs accelerate gelation compared to the more hydrophilic PAs due to a higher 65 concentration of these nuclei. The rate of gelation could be tuned by altering the bulkiness of the amino acids used and the hydrophobicity of the overall peptide sequence.

(a)

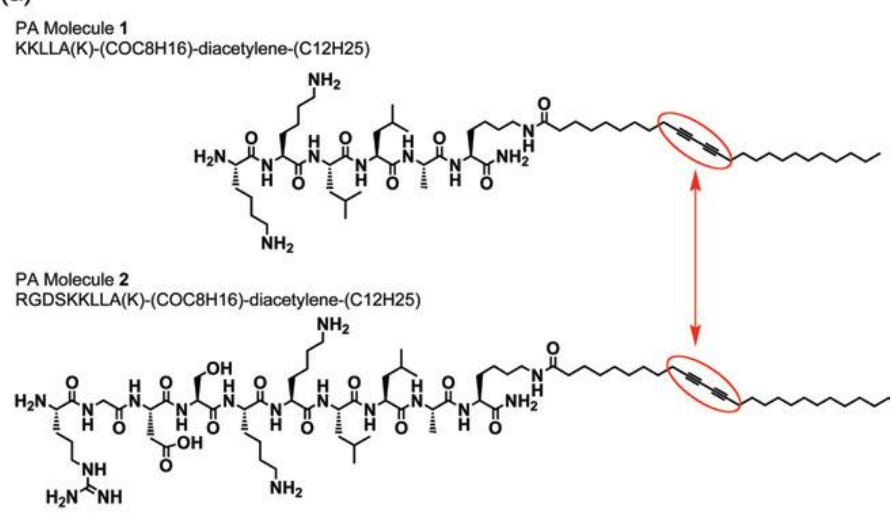

(b)

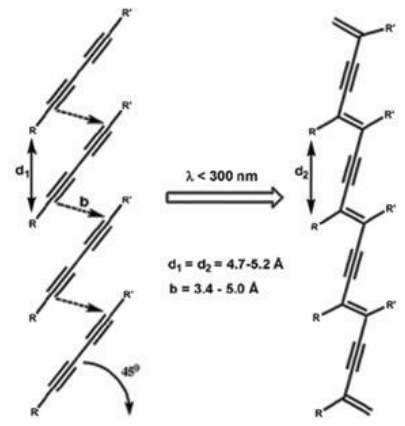

Figure 11. (a) Molecular structure of two PA molecules incorporating a photocrosslinkable diacetylene segment 70 (circled). (b) Illustration of the polymerisation reaction of the diacetylene segments when UV irradiated. Figure taken from Mata et al. ${ }^{179}$ Reproduced by permission of The Royal Society of Chemistry.

75 PAs have been proven to be effective scaffolds for crystal nucleation and consequent directed growth. Additionally, Stupp's group have shown that lithographical techniques can be employed to control the structure of the PA nanofibrous networks. ${ }^{179,} 180$ By combining lithography with structure80 directing PAs, one can begin to control the nanoparticle morphology of a wide variety of materials, including metals like gold. ${ }^{181}$ This latter example, controlling the growth of gold nanoparticles, actually uses a subtly different class of PA as the structure-directing scaffold. The PA consists of only 85 two major components; the aliphatic tail and a positively charged amino acid or dipeptide head group. These materials, pioneered by Das, have potential as vectors for antimicrobial activity due to the ability of cationic ammonium amphiphiles to penetrate cell membranes. ${ }^{112,182,183}$

90 Peptide chains can also be "grown" orthogonally to the original peptidic segment of a PA to yield branched PAs. 
These self-assemble in the same manner as conventional PAs to afford nanofibres (which consequently entangle to produce hydrogels), but additionally allow the multiaddition of functional groups, such as MRI agents ${ }^{98,184}$ (to non-invasively 5 image scaffolds as a means of in vivo fate mapping, tracking how the PAs will behave under different physiological conditions), bioactive epitopes ${ }^{97,} 185$ and catalytic groups. ${ }^{186}$ The major advantage of branched PAs over conventional PAs is that they offer a higher density of binding sites for 10 biological activity. Additionally, the extensive work carried out by Stupp suggests that they also provide further control over the self-assembly process.

There is increasing interest in peptide-amphiphiles, due to their biocompatibility, specific self-assembling behaviour and 15 highly controllable molecular composition. ${ }^{187}$ As progress continues in this field, the biomedical applications of such hydrogels become more diverse.

\subsection{Polymer-peptide conjugates}

20 Although the range of applications of PAs is broad, there is an upper limit due to the simplicity of the hydrocarbon tail; in that its sole function is to drive self-assembly. Modifying a peptide with a polymer, however, means that one can introduce a whole host of features into the biomaterial. The 25 resulting polymer-peptide conjugate boasts versatility in both bioactivity (from control over the specific amino acid sequence in the peptidic moiety) and physical properties (from control of the polymer functionality, architecture, biocompatibilty, protein-adsorption resistivity and molecular 30 weight). Such properties inferred from polymer incorporation can include prolonged in vivo lifetimes, stimuli-responsive behaviour and increased thermal stability. Additionally, it is well documented that the viscoelasticity of the extracellular matrix (or synthetic hydrogel substitute) affects cell 35 behaviour, ${ }^{188-192}$ therefore it is vital we can control the mechanical stiffness of biomaterials intended for cellular uptake. There are a plethora of examples whereby polymerpeptide conjugates self-aggregate into fibrillar ( $\beta$-sheet) or helical substructures and it is very probable that such 40 materials would form "bioinspired" hydrogels under the appropriate conditions. ${ }^{46,94,101-103,110,193-197}$ However, these reports, and many more, do not mention the study of the hydrogel formation of their material and are therefore beyond the scope of this review and the reader is directed elsewhere. ${ }^{2}$

${ }_{45}$ This area is calling out for further work, with the library of materials being available; they just have not yet been tested for this purpose. In this section we review work which specifically discusses polymer-peptide conjugates as hydrogelators only.

50 Chung et al. ${ }^{198}$ have created a polymer-peptide hydrogel to enhance bone formation, as exempfiled in mice. GRGDS, the common cell binding motif, was integrated into a thermoresponsive organophosphazene repeat unit. The final polymer-peptide conjugate had the thermal sensitivity of the 55 synthetic polymer; being an injectable fluid at room temperature and a viscoelastic scaffold at body temperature, and the bioactivity of the GRGDS sequence. Consequently, the fluid was injected into a mouse, where it spontaneously self-assembled to create a bioactive gel that was used as a 60 stem cell scaffold to induce osteogenic differentiation. Such injectable, yet biodegradable, material promises for future application in human cell delivery, as discussed in detail in a recent review by Chung and Park. ${ }^{199}$

Mei et al. ${ }^{105}$ attached the same bioactive epitope, GRGDS, 65 to a poly(hydroxyethyl methacrylate), PHEMA, chain and tested the cell activity within the hydrogel structure. The incorporation of a small amount of peptide (approximate polymer:peptide weight ratio of $6: 1$ ) caused the hydrogel to induce cell adhesion and spreading. It is noteworthy that the 70 authors did not report any optimisation of this level of peptide integration and could indeed function at even lower amounts. Such low peptide loadings suggest that the mechanical properties of conjugates would not be drastically altered when incorporating bioactivity. Moreover, the synthetic strategy 75 employed by the group (growing the polymer from the peptide by ATRP) extends the scope of available polymers and molecular weights. This provides even more control over the hydrogel properties. It is somewhat suprising therefore that this approach has not been used to produce a wide range of 80 polymer-peptide constructs for controlled hydrogel synthesis. Using a convergent approach to construct PEO-tetrapeptide conjugates, Tzokova et al. ${ }^{50},{ }^{51}$ investigated the PEO incorporation to look at the self-assembly of the tetraphenylalanine and tetravaline-containing compounds in 85 water. Hydrogels were formed (from nanotubes with $\beta$-sheets) using phenylalanine with sufficiently low levels of PEO content (namely $\mathrm{PEO}_{7}$-PhePhePhePhe). Higher PEO loadings caused the conjugates to adopt a variety of structures, such as wormlike micelles, more similar to those formed by 90 conventional amphiphilic block copolymers. ${ }^{50}$ Conversely, conjugates containing valine did not form hydrogels at all concentrations tested. Instead they produced plaque-like aggregates due to the stronger $\beta$-sheet forming propensity of valine. Kopecek's group ${ }^{52,109,120}$ have exploited the formation ${ }_{95}$ of $\alpha$-helices to physically crosslink stimuli-responsive polymers. The peptidic physical crosslinks provided structural integrity to afford controllable and reversible hydrogels, as shown in Figure 12. $N$-(2-Hydroxypropyl)methacrylamide (HPMA) was copolymerised with a methacrylamide peptide 100 macromonomer $^{109}$ or a functionalised monomer capable of accommodating a peptide graft $^{52,120}$ to produce comb-like conjugates. The authors illustrated the importance of the make-up of the peptidic component for producing hydrogels. Peptides, based on helical-forming heptads, were found to 105 induce hydrogelation when comprised of four heptad repeats or more. Furthermore, coiled-coils were observed when the peptide grafts consisted of a minimum of five heptads. Hydrogels were formed at low concentrations (> $5.54 \mathrm{mg} / \mathrm{mL}$ ) of the same material, but could also be produced at much 110 lower concentrations (> $1 \mathrm{mg} / \mathrm{mL}$ ), when using equimolar mixtures of oppositely charged peptide combs. Moreover, the use of HPMA inferred a number of advantages to the bioinspired hydrogels. For example, the materials were shown to exhibit thermoresponsive behaviour in addition to having 115 higher thermal stabilities. This work highlights the degree of 
control associated with polymer-peptide conjugates. The level of peptide incorporation and type of peptide sequence can also control the mechanical properties of the material in addition to control over the stimuli-response and other physicochemical 5 properties with the polymer moiety.

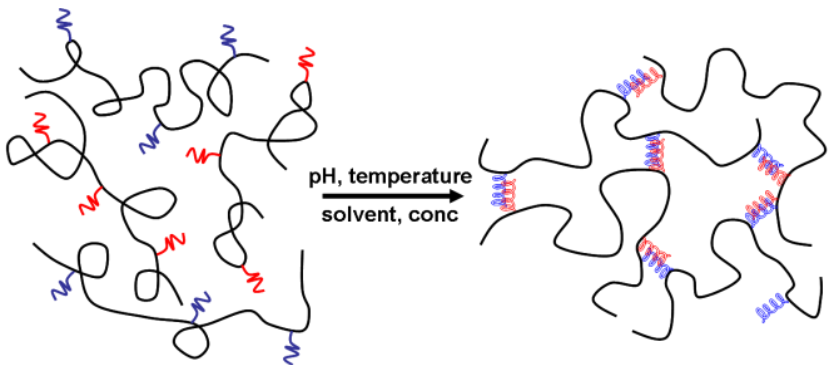

Figure 12. Schematic of the hydrogelation process through anitparallel coiled-coil aggregation, illustrating one of the many possible conformations of such helical physical crosslinks. Adapted with permission from Yang et al. ${ }^{120}$ ${ }_{10}$ Copyright 2006 American Chemical Society.

The incorporation of a polymer into a peptide has been shown to be extremely effective in changing the chemical and physical properties of peptide epitopes by using polymers of 15 specific types. Another important feature of a polymer-peptide conjugate is its final architecture i.e. the manner in which the polymer is attached. For example, Ganesh et al. ${ }^{200}$ synthesised two conjugates comprising oligo(ethylene oxide) and triisoleucine; one as a diblock "copolymer" and one as a 20 triblock with the peptide segment bridging two oligo(ethylene oxide) segments. The diblock entity was shown to form rigid rods (with antiparallel stacking), whereas the triblock was shown to create a non-covalently bound mesh of parallel $\beta$ sheets. Both materials were shown to form gels, yet the 25 diblock showed increased solubility in alcohols compared to the triblock and is expected to have much lower mechanical strength (due to the lack of crosslinking). This is a very interesting example of how subtleties in primary chain architecture can drastically affect the final hydrogel 30 properties. In a similar example, Jing et al. ${ }^{53}$ showed that although their PEO-peptide diblock copolymer was a viscous liquid, the peptide-PEO-peptide triblock counterpart formed viscoelastic hydrogels due to the association of the peptide endgroups into coiled-coils. This work clearly demonstrates 35 that when designing biomaterials one must not only carefully select the peptide and polymer, but must also construct the conjugate appropriately.

Modified peptides, which also fit into the scope of this review, but are not strictly polymer-peptide conjugates have 40 been studied by Kelly and coworkers. ${ }^{201}$ Briefly, the authors attached two peptide blocks to a dibenzofuran linker, which preorganised the peptidic molecules into dimers. The dimers further self-assembled into $\beta$-sheets, which formed fibrils with a hydrophobic edge to drive filament assembly. This work, 45 published in 2000 , was instrumental to a vast proportion of the work discussed in this review. They discuss the concepts underpinning $\beta$-sheet fibril formation, which is vitally important for controlling the assembly process, particularly for in vivo applications.
50 It is worth noting that polymer incorporation has also been used to inhibit the gelation of peptides. ${ }^{93,202-205}$ Diblocks and triblocks containing PEO blocks flanking peptide segments have been synthesised in order to prevent lateral fibril-fibril aggregation into macromolecular assemblies. The peptidic 55 domains on individual fibrils cannot approach each other due to the tethered polymer chains. This work is particularly useful in controlling amyloid fibre formation, an irreversible process well known to be the major contributor to Alzheimer's disease. Controlling the reversible formation of 60 such plaques, for example, is seen to be a step towards combating such devastating maladies in the near future.

\section{Conclusions and Future Outlook}

Many peptide-conjugates can be used to prepare hydrogels. Whilst falling into three main classes, it is clear that the 65 structural diversity is extremely large, with an array of different molecules capable of forming a gel on assembly. In many ways, this structural diversity is one of the greatest challenges to the field. Whilst all the examples cited above clearly demonstrate highly successful means of preparing 70 hydrogels, it is difficult to those outside the field to appreciate the differences between the systems. Indeed, in many cases, the mechanical properties of the hydrogels formed are not reported, which makes comparing the final gels prepared extremely difficult. Hence, whilst many of these hydrogelators 75 have been used to prepare gels for cell scaffolds for example, a direct comparison is in many cases impossible. On top of this, the design of hydrogelators is also difficult. It is often unclear why one peptide-conjugate will successfully form hydrogels whilst a structurally similar analogue will not. For 80 example, Fmoc-PheGly is a well-known hydrogelator, ${ }^{140}$ whilst Fmoc-GlyPhe (where the order of the amino acids has been swapped) does not form gels. ${ }^{138,140}$ Hence, designing a successful hydrogelator from first principles is often difficult. Further complications arise from recent observations that the 85 method of assembly can lead to gels with different properties. In many of these cases, it is likely that the method of assembly is an often-overlooked, but crucial parameter that requires further investigation. Nevertheless, these classes of peptide-conjugates can be used to prepare hydrogels with a 90 range of properties and, with the current interest in these molecules and the hydrogels themselves, we anticipate that great strides in understanding will occur in the near future.

\section{References}

$95{ }^{a}$ Department of Chemistry, University of Liverpool, Crown Street,
Liverpool, L69 7ZD, UK. E-mail: d.j.adams@ @iverpool.ac.uk
${ }^{b}$ Chemical Engineering and Applied Chemistry, Aston University, Aston
Triangle, Birmingham, B4 7ET, UK. E-mail: p.d.topham@aston.ac.uk

1001 B. V. Slaughter, S. S. Khurshid, O. Z. Fisher, A. Khademhosseini and N. A. Peppas, Adv. Mater., 2009, 21, 3307-3329.

2 J. Kopecek, J. Pol. Sci. A Pol. Chem., 2009, 47, 5929-5946.

3 M. L. Davies and B. J. Tighe, Selective Electrode Rev., 1991, 13, 159-226.

1054 Y. Nagai, L. D. Unsworth, S. Koutsopoulos and S. G. Zhang, J. Controlled Release, 2006, 115, 18-25. 
5 S. R. Veith, E. Hughes and S. E. Pratsinis, J. Controlled Release, 2004, 99, 315-327.

6 J. Naskar, G. Palui and A. Banerjee, J. Phys. Chem. B, 2009, 113, 11787-11792.

57 R. Langer and J. P. Vacanti, Science, 1993, 260, 920-926.

8 Y. D. Wang, G. A. Ameer, B. J. Sheppard and R. Langer, Nature Biotechnol., 2002, 20, 602-606.

9 L. Almany and D. Seliktar, Biomaterials, 2005, 26, 2467-2477.

10 J. K. Tessmar and A. M. Gopferich, Adv. Drug Del. Rev., 2007, 59, 274-291.

11 T. C. Holmes, S. de Lacalle, X. Su, G. S. Liu, A. Rich and S. G. Zhang, Proc. Nat. Acad. Sci., 2000, 97, 6728-6733.

12 J. Kisiday, M. Jin, B. Kurz, H. Hung, C. Semino, S. Zhang and A. J. Grodzinsky, Proc. Nat. Acad. Sci., 2002, 99, 9996-10001.

1513 S. G. Zhang, F. Gelain and X. J. Zhao, Seminars in Cancer Biology, 2005, 15, 413-420.

14 M. E. Davis, J. P. M. Motion, D. A. Narmoneva, T. Takahashi, D. Hakuno, R. D. Kamm, S. G. Zhang and R. T. Lee, Circulation, 2005, 111, $442-450$.

2015 D. A. Narmoneva, O. Oni, A. L. Sieminski, S. G. Zhang, J. P. Gertler, R. D. Kamm and R. T. Lee, Biomaterials, 2005, 26, 4837 4846.

16 M. A. Bokhari, G. Akay, S. G. Zhang and M. A. Birch, Biomaterials, 2005, 26, 5198-5208.

2517 J. P. Schneider, D. J. Pochan, B. Ozbas, K. Rajagopal, L. Pakstis and J. Kretsinger, J. Am. Chem. Soc., 2002, 124, 15030-15037.

18 R. G. Ellis-Behnke, Y. X. Liang, S. W. You, D. K. C. Tay, S. G. Zhang, K. F. So and G. E. Schneider, Proc. Nat. Acad. Sci., 2006, 103, 5054-5059.

3019 J. K. Kretsinger, L. A. Haines, B. Ozbas, D. J. Pochan and J. P. Schneider, Biomaterials, 2005, 26, 5177-5186.

20 H. Yokoi, T. Kinoshita and S. G. Zhang, Proc. Nat. Acad. Sci., 2005, 102, 8414-8419.

21 G. A. Silva, C. Czeisler, K. L. Niece, E. Beniash, D. A. Harrington, J.

35 A. Kessler and S. I. Stupp, Science, 2004, 303, 1352-1355.

22 E. S. Place, J. H. George, C. K. Williams and M. M. Stevens, Chem. Soc. Rev., 2009, 38, 1139-1151.

23 J. D. Hartgerink, E. Beniash and S. I. Stupp, Science, 2001, 294, 1684-1688.

4024 B. J. Tighe, Chemistry \& Industry, 1981, 796-800.

25 P. H. Corkhill, C. J. Hamilton and B. J. Tighe, Crit. Rev. Biocompatibility, 1990, 5, 363-436.

26 A. Chenite, C. Chaput, D. Wang, C. Combes, M. D. Buschmann, C. D. Hoemann, J. C. Leroux, B. L. Atkinson, F. Binette and A. Selmani, Biomaterials, 2000, 21, 2155-2161.

27 J. L. Drury and D. J. Mooney, Biomaterials, 2003, 24, 4337-4351.

28 N. A. Peppas, P. Bures, W. Leobandung and H. Ichikawa, Eur. J. Pharm. Biopharm., 2000, 50, 27-46.

29 J. L. Ifkovits and J. A. Burdick, Tissue Eng., 2007, 13, 2369-2385.

5030 M. George and R. G. Weiss, Acc. Chem. Res., 2006, 39, 489-497.

31 R. V. Ulijn and A. M. Smith, Chem. Soc. Rev., 2008, 37, 664-675.

32 S. G. Zhang, Nature Biotech., 2003, 21, 1171-1178.

33 K. Rajagopal and J. P. Schneider, Curr. Op. Struct. Bio., 2004, 14, 480-486.

5534 M. S. Lamm, K. Rajagopal, J. P. Schneider and D. J. Pochan, J. Am. Chem. Soc., 2005, 127, 16692-16700.

35 B. Ozbas, J. Kretsinger, K. Rajagopal, J. P. Schneider and D. J. Pochan, Macromolecules, 2004, 37, 7331-7337.

36 K. Rajagopal, B. Ozbas, D. J. Pochan and J. P. Schneider, Eur.

60 Biophys. J. Biophys. Lett., 2006, 35, 162-169.

37 D. J. Pochan, J. P. Schneider, J. Kretsinger, B. Ozbas, K. Rajagopal and L. Haines, J. Am. Chem. Soc., 2003, 125, 11802-11803.

38 L. A. Haines, K. Rajagopal, B. Ozbas, D. A. Salick, D. J. Pochan and J. P. Schneider, J. Am. Chem. Soc., 2005, 127, 17025-17029.

6539 M. R. Caplan, P. N. Moore, S. G. Zhang, R. D. Kamm and D. A. Lauffenburger, Biomacromolecules, 2000, 1, 627-631.

40 M. R. Caplan, E. M. Schwartzfarb, S. G. Zhang, R. D. Kamm and D. A. Lauffenburger, Biomaterials, 2002, 23, 219-227.

41 S. G. Zhang, T. C. Holmes, C. M. Dipersio, R. O. Hynes, X. Su and

70 A. Rich, Biomaterials, 1995, 16, 1385-1393.
42 A. Aggeli, M. Bell, L. M. Carrick, C. W. G. Fishwick, R. Harding, P. J. Mawer, S. E. Radford, A. E. Strong and N. Boden, J. Am. Chem. Soc., 2003, 125, 9619-9628.

43 V. Kayser, D. A. Turton, A. Aggeli, A. Beevers, G. D. Reid and G. S. Beddard, J. Am. Chem. Soc., 2004, 126, 336-343.

44 A. Aggeli, M. Bell, N. Boden, L. M. Carrick and A. E. Strong, Angew Chem. Int. Ed., 2003, 42, 5603-5606.

45 J. H. Collier and P. B. Messersmith, Bioconjugate Chem., 2003, 14, $748-755$

8046 J. H. Collier and P. B. Messersmith, Adv. Mater., 2004, 16, 907-910.

47 S. Dos Santos, A. Chandravarkar, B. Mandal, R. Mimna, K. Murat, L. Saucede, P. Tella, G. Tuchscherer and M. Mutter, J. Am. Chem. Soc., 2005, 127, 11888-11889.

48 S. Ramachandran, Y. Tseng and Y. B. Yu, Biomacromolecules, 2005, 6, 1316-1321.

49 S. Rarnachandran, P. Flynn, Y. Tseng and Y. B. Yu, Chem. Mater. 2005, 17, 6583-6588.

50 N. Tzokova, C. M. Fernyhough, M. F. Butler, S. P. Armes, A. J. Ryan, P. D. Topham and D. J. Adams, Langmuir, 2009, 25, 1108211089.

51 N. Tzokova, C. M. Fernyhouph, P. D. Topham, N. Sandon, D. J. Adams, M. F. Butler, S. P. Armes and A. J. Ryan, Langmuir, 2009, 25, 2479-2485

52 J. Y. Yang, C. Y. Xu, P. Kopeckova and J. Kopecek, Macromol. Biosci., 2006, 6, 201-209.

53 P. Jing, J. S. Rudra, A. B. Herr and J. H. Collier, Biomacromolecules, 2008, 9, 2438-2446.

54 T. J. Deming, Peptide Hybrid Polymers, 2006, 202, 1-18.

55 W. A. Petka, J. L. Harden, K. P. McGrath, D. Wirtz and D. A. Tirrell, Science, 1998, 281, 389-392.

56 C. Y. Xu and J. Kopecek, Pharm. Res., 2008, 25, 674-682.

57 C. Y. Xu, V. Breedveld and J. Kopecek, Biomacromolecules, 2005, 6, 1739-1749.

58 S. G. Zhang, D. M. Marini, W. Hwang and S. Santoso, Curr. Op. 105 Chem. Bio., 2002, 6, 865-871.

59 P. Chen, Coll. Surf. A, 2005, 261, 3-24.

60 J. H. Collier, B. H. Hu, J. W. Ruberti, J. Zhang, P. Shum, D. H. Thompson and P. B. Messersmith, J. Am. Chem. Soc., 2001, 123, 9463-9464.

11061 L. Haines-Butterick, K. Rajagopal, M. Branco, D. Salick, R. Rughani, M. Pilarz, M. S. Lamm, D. J. Pochan and J. P. Schneider, Proc. Nat Acad. Sci., 2007, 104, 7791-7796.

62 E. J. Leon, N. Verma, S. G. Zhang, D. A. Lauffenburger and R. D. Kamm, J. Biomater. Sci., 1998, 9, 297-312.

11563 Y. J. Zeng, J. Yang, K. Huang, Z. H. Lee and X. Y. Lee, J. Biomechanics, 2001, 34, 533-537.

64 K. T. Nguyen and J. L. West, Biomaterials, 2002, 23, 4307-4314.

65 D. W. Hutmacher, J. Biomater. Sci., 2001, 12, 107-124.

66 C. C. Lin and A. T. Metters, Adv. Drug Del. Rev., 2006, 58, 13791408.

67 S. Sershen and J. West, Adv. Drug Del. Rev., 2002, 54, 1225-1235.

68 R. H. Li, D. H. Altreuter and F. T. Gentile, Biotech. Bioeng., 1996, 50, 365-373.

69 P. Calvert, Adv. Mater., 2009, 21, 743-756.

12570 S. R. Raghavan and B. H. Cipriano, Molecular Gels, 2006, 241-252.

71 D. J. Adams, M. F. Butler, W. J. Frith, M. Kirkland, L. Mullen and P. Sanderson, Soft Matter, 2009, 5, 1856-1862.

72 T. G. Metzger, The Rheology Handbook, Vincentz Verlag, Hannover, 2006.

13073 G. M. Kavanagh and S. B. Ross-Murphy, Prog. Pol. Sci., 1998, 23, 533-562.

74 H. H. Winter and M. Mours, Neutron Spin Echo Spectroscopy Viscoelasticity Rheology, 1997, 134, 165-234.

75 F. C. Mackintosh, J. Kas and P. A. Janmey, Phys. Rev. Lett., 1995 75, 4425-4428.

76 B. Ozbas, K. Rajagopal, J. P. Schneider and D. J. Pochan, Phys. Rev. Lett., 2004, 93.

77 M. A. Greenfield, J. R. Hoffman, M. Olvera de la Cruz and S. I. Stupp, Langmuir, 2010, DOI: 10.1021/la9030969.

14078 T. Larsen, K. Schultz and E. M. Furst, Korea-Australia Rheology J., 2008, 20, 165-173. 
79 V. Breedveld and D. J. Pine, J. Mater. Sci., 2003, 38, 4461-4470.

80 P. Cicuta and A. M. Donald, Soft Matter, 2007, 3, 1449-1455.

81 S. Sutton, N. L. Campbell, A. I. Cooper, M. Kirkland, W. J. Frith and D. J. Adams, Langmuir, 2009, 25, 10285-10291.

582 A. Mahler, M. Reches, M. Rechter, S. Cohen and E. Gazit, Adv. Mater., 2006, 18, 1365-1370.

83 N. Amdursky, R. Orbach, E. Gazit and D. Huppert, J. Phys. Chem. C, 2009, 113, 19500-19505.

84 H. R. Marsden and A. Kros, Macromol. Biosci., 2009, 9, 939-951.

1085 J. Nicolas, G. Mantovani and D. M. Haddleton, Macromol. Rapid Commun., 2007, 28, 1083-1111.

86 M. A. Gauthier and H. A. Klok, Chem. Commun., 2008, 2591-2611.

87 H. A. Klok, Angew. Chem. Int. Ed., 2002, 41, 1509-1513.

88 N. L. Goeden-Wood, J. D. Keasling and S. J. Muller, Macromolecules, 2003, 36, 2932-2938.

89 Y. Qu, S. C. Payne, R. P. Apkarian and V. P. Conticello, J. Am. Chem. Soc., 2000, 122, 5014-5015.

90 D. Lowik, L. Ayres, J. M. Smeenk and J. C. M. Van Hest, Peptide Hybrid Polymers, 2006, 202, 19-52.

2091 C. Montalbetti and V. Falque, Tet., 2005, 61, 10827-10852.

92 R. B. Merrifield, J. Am. Chem. Soc., 1963, 85, 2149-2154.

93 T. S. Burkoth, T. L. S. Benzinger, D. N. M. Jones, K. Hallenga, S. C Meredith and D. G. Lynn, J. Am. Chem. Soc., 1998, 120, 7655-7656.

94 J. Hentschel, E. Krause and H. G. Borner, J. Am. Chem. Soc., 2006, 128, 7722-7723.

95 I. C. Reynhout, D. Lowik, J. C. M. van Hest, J. Cornelissen and R. J. M. Nolte, Chem. Commun., 2005, 602-604.

96 T. D. Sargeant, M. O. Guler, S. M. Oppenheimer, A. Mata, R. L. Satcher, D. C. Dunand and S. I. Stupp, Biomaterials, 2008, 29, 161171.

97 M. O. Guler, S. Soukasene, J. F. Hulvat and S. I. Stupp, Nano Lett., $2005, \mathbf{5}, 249-252$

98 S. R. Bull, M. O. Guler, R. E. Bras, T. J. Meade and S. I. Stupp, Nano Lett., 2005, 5, 1-4.

3599 H. A. Behanna, J. Donners, A. C. Gordon and S. I. Stupp, J. Am. Chem. Soc., 2005, 127, 1193-1200.

100 H. Rettig, E. Krause and H. G. Borner, Macromol. Rapid Commun., 2004, 25, 1251-1256.

101 L. Ayres, P. Hans, J. Adams, D. Lowik and J. C. M. van Hest, J.

40 Polym. Sci. Pol. Chem., 2005, 43, 6355-6366.

102 M. G. J. ten Cate, H. Rettig, K. Bernhardt and H. G. Borner, Macromolecules, 2005, 38, 10643-10649.

103 J. Hentschel, M. G. J. ten Cate and H. G. Borner, Macromolecules, 2007, 40, 9224-9232.

45104 M. L. Becker, J. Q. Liu and K. L. Wooley, Chem. Commun., 2003, 180-181.

105 Y. Mei, K. L. Beers, H. C. M. Byrd, D. L. Vanderhart and N. R. Washburn, J. Am. Chem. Soc., 2004, 126, 3472-3476.

106 S. A. Bencherif, H. Gao, A. Srinivasan, D. J. Siegwart, J. O.

50 Hollinger, N. R. Washburn and K. Matyjaszewski, Biomacromolecules, 2009, 10, 1795-1803.

107 B. H. Hu, J. Su and P. B. Messersmith, Biomacromolecules, 2009 , 10, 2194-2200.

108 J. Zimmermann, K. Bittner, B. Stark and R. Mulhaupt, Biomaterials, 2002, 23, 2127-2134

109 K. Wu, J. Y. Yang, C. Konak, P. Kopeckova and J. Kopecek, Macromol. Chem. Phys., 2008, 209, 467-475.

110 L. Ayres, M. R. J. Vos, P. Adams, I. O. Shklyarevskiy and J. C. M. van Hest, Macromolecules, 2003, 36, 5967-5973.

60111 R. S. Burke and S. H. Pun, Bioconj. Chem., 2010, DOI: $10.1021 /$ bc 9003662 .

112 S. Roy, A. Dasgupta and P. K. Das, Langmuir, 2007, 23, 1176911776.

113 F. M. Veronese, Biomaterials, 2001, 22, 405-417.

65114 C. J. Hawker, V. V. Fokin, M. G. Finn and K. B. Sharpless, Aust. J. Chem., 2007, 60, 381-383.

115 J. F. Lutz and Z. Zarafshani, Adv. Drug Del. Rev., 2008, 60, 958-970.

116 R. J. Pounder, M. J. Stanford, P. Brooks, S. P. Richards and A. P. Dove, Chem. Commun., 2008, 5158-5160.

70117 M. Li, P. De, S. R. Gondi and B. S. Sumerlin, J. Polym. Sci. Pol. Chem., 2008, 46, 5093-5100.
118 J. F. Lutz, Angew. Chem. Int. Ed., 2007, 46, 1018-1025.

119 M. Meldal and C. W. Tornoe, Chem. Rev., 2008, 108, 2952-3015.

120 J. Y. Yang, C. Y. Xu, C. Wang and J. Kopecek, Biomacromolecules, 2006, 7, 1187-1195.

121 M. J. Roberts, M. D. Bentley and J. M. Harris, Adv. Drug Del. Rev., 2002, 54, 459-476.

122 K. L. Niece, J. D. Hartgerink, J. Donners and S. I. Stupp, J. Am. Chem. Soc., 2003, 125, 7146-7147.

80123 S. E. Paramonov, H. W. Jun and J. D. Hartgerink, J. Am. Chem. Soc., 2006, 128, 7291-7298.

124 K. L. Niece, C. Czeisler, V. Sahni, V. Tysseling-Mattiace, E. T. Pashuck, J. A. Kessler and S. I. Stupp, Biomaterials, 2008, 29, 45014509.

85125 J. D. Hartgerink, E. Beniash and S. I. Stupp, Proc. Nat. Acad. Sci., 2002, 99, 5133-5138

126 J. D. Tovar, R. C. Claussen and S. I. Stupp, J. Am. Chem. Soc., 2005, 127, 7337-7345.

127 J. M. Anderson, A. Andukuri, D. J. Lim and H. W. Jun, ACS Nano, 2009, 3, 3447-3454.

128 N. S. de Groot, T. Parella, F. X. Aviles, J. Vendrell and S. Ventura, Biophys. J., 2007, 92, 1732-1741.

129 J. J. Panda, A. Mishra, A. Basu and V. S. Chauhan, Biomacromolecules, 2008, 9, 2244-2250.

95130 J. Ryu and C. B. Park, Angew. Chem. Int. Ed., 2009, 48, 4820-4823.

131 M. Reches and E. Gazit, Nature Nanotech., 2006, 1, 195-200.

132 J. Kim, T. H. Han, Y.-I. Kim, J. S. Park, J. Choi, D. G. Churchill, S. O. Kim and H. Ihee, Adv. Mater., 2010, 22, 583-587.

133 A. Comotti, S. Bracco, G. Distefano and P. Sozzani, Chem. Commun., 2009, 284-286.

134 Y. Zhang, H. W. Gu, Z. M. Yang and B. Xu, J. Am. Chem. Soc., 2003, 125, 13680-13681

135 Y. Zhang, Z. M. Yang, F. Yuan, H. W. Gu, P. Gao and B. Xu, J. Am. Chem. Soc., 2004, 126, 15028-15029.

105136 Z. M. Yang, G. L. Liang, M. L. Ma, Y. Gao and B. Xu, J. Mater Chem., 2007, 17, 850-854.

137 R. Vegners, I. Shestakova, I. Kalvinsh, R. M. Ezzell and P. A. Janmey, J. Pept. Sci., 1995, 1, 371-378.

138 V. Jayawarna, M. Ali, T. A. Jowitt, A. E. Miller, A. Saiani, J. E. Gough and R. V. Ulijn, Adv. Mater., 2006, 18, 611-614.

139 T. Liebmann, S. Rydholm, V. Akpe and H. Brismar, Bmc Biotechnology, 2007, 7.

140 R. Orbach, L. Adler-Abramovich, S. Zigerson, I. Mironi-Harpaz, D. Seliktar and E. Gazit, Biomacromolecules, 2009, 10, 2646-2651.

115141 V. Jayawarna, S. M. Richardson, A. R. Hirst, N. W. Hodson, A. Saiani, J. E. Gough and R. V. Ulijn, Acta Biomaterialia, 2009, 5, 934-943.

142 A. M. Smith, R. J. Williams, C. Tang, P. Coppo, R. F. Collins, M. L. Turner, A. Saiani and R. V. Ulijn, Adv. Mater., 2008, 20, 37-41.

120143 M. Zhou, A. M. Smith, A. K. Das, N. W. Hodson, R. F. Collins, R. V. Ulijn and J. E. Gough, Biomaterials, 2009, 30, 2523-2530.

144 L. A. Carpino and G. Y. Han, J. Org. Chem., 1972, 37, 3404-3409.

145 C. Tang, A. M. Smith, R. F. Collins, R. V. Ulijn and A. Saiani, Langmuir, 2009, 25, 9447-9453.

125146 Z. M. Yang, G. L. Liang, M. L. Ma, Y. Gao and B. Xu, Small, 2007, 3, 558-562.

147 A. M. Hung and S. I. Stupp, Langmuir, 2009, 25, 7084-7089.

148 D. J. Adams, L. Mullen, M. Berta, L. Chen and W. J. Frith, Soft Matter, 2010, DOI: 10.1039/b921863g.

130149 Z. M. Yang, H. W. Gu, D. G. Fu, P. Gao, J. K. Lam and B. Xu, Adv. Mater., 2004, 16, 1440-1444.

150 Z. A. C. Schnepp, R. Gonzalez-McQuire and S. Mann, Adv. Mater. 2006, 18, 1869-1872

151 R. A. Laskowski, J. M. Thornton and M. J. E. Sternberg, Biochem Soc. Trans., 2009, 37, 723-726.

152 S. Toledano, R. J. Williams, V. Jayawarna and R. V. Ulijn, J. Am. Chem. Soc., 2006, 128, 1070-1071.

153 A. K. Das, R. Collins and R. V. Ulijn, Small, 2008, 4, 279-287.

154 R. J. Williams, A. M. Smith, R. Collins, N. Hodson, A. K. Das and R. V. Ulijn, Nature Nanotech., 2009, 4, 19-24.

155 A. K. Das, A. R. Hirst and R. V. Ulijn, Faraday Discuss., 2009, 143, 293-303. 
156 K. J. Channon, G. L. Devlin, S. W. Magennis, C. E. Finlayson, A. K. Tickler, C. Silva and C. E. MacPhee, J. Am. Chem. Soc., 2008, 130, 5487-5491.

157 G. Cheng, V. Castelletto, C. M. Moulton, G. E. Newby and I. W. Hamley, Langmuir, 2010, DOI: 10.1021/la903678e.

158 M. Ma, Y. Kuang, G. Yuan, Y. Zhang, P. Gao and B. Xu, J. Am. Chem. Soc., 2010, 132, 2719-2728.

159 Z. M. Yang, G. L. Liang and B. Xu, Chem. Commun., 2006, 738-740.

160 D. Seebach and J. L. Matthews, Chem. Commun., 1997, 2015-2022.

10161 H. W. Jun, V. Yuwono, S. E. Paramonov and J. D. Hartgerink, $A d v$. Mater., 2005, 17, 2612-2617.

162 G. L. Liang, Z. M. Yang, R. J. Zhang, L. H. Li, Y. J. Fan, Y. Kuang, Y. Gao, T. Wang, W. W. Lu and B. Xu, Langmuir, 2009, 25, 84198422.

15163 L. Chen, K. Morris, A. Laybourn, D. Elias, M. R. Hicks, A. Rodger, L. C. Serpell and D. J. Adams, Langmuir, 2010, DOI: 10.1021/la903694a.

164 D. Lowik and J. C. M. van Hest, Chem. Soc. Rev., 2004, 33, 234-245.

165 M. W. Matsen and F. S. Bates, Macromolecules, 1996, 29, 1091201098 .

166 S. Ghanaati, M. J. Webber, R. E. Unger, C. Orth, J. F. Hulvat, S. E. Kiehna, M. Barbeck, A. Rasic, S. I. Stupp and C. J. Kirkpatrick, Biomaterials, 2009, 30, 6202-6212.

167 H. Storrie, M. O. Guler, S. N. Abu-Amara, T. Volberg, M. Rao, B.

25 Geiger and S. I. Stupp, Biomaterials, 2007, 28, 4608-4618.

168 K. M. Galler, A. Cavender, V. Yuwono, H. Dong, S. Shi, G. Schmalz, J. D. Hartgerink and R. N. D'Souza, Tissue Engineering Part A, 2008, 14, 2051-2058.

169 Z. W. Zou, Q. X. Zheng, Y. C. Wu, W. Song and B. Wu, Mater. Sci. 30 Eng. C, 2009, 29, 2099-2103.

170 J. Y. Lee, J. E. Choo, Y. S. Choi, J. S. Suh, S. J. Lee, C. P. Chung and Y. J. Park, Biomaterials, 2009, 30, 3532-3541.

171 H. K. Lee, S. Soukasene, H. Z. Jiang, S. M. Zhang, W. C. Feng and S. I. Stupp, Soft Matter, 2008, 4, 962-964.

35172 T. Muraoka, C. Y. Koh, H. G. Cui and S. I. Stupp, Angew. Chem. Int. Ed., 2009, 48, 5946-5949.

173 K. Rajangam, M. S. Arnold, M. A. Rocco and S. I. Stupp, Biomaterials, 2008, 29, 3298-3305.

174 E. D. Spoerke, S. G. Anthony and S. I. Stupp, Adv. Mater., 2009, 21, 425-430.

175 J. K. Kim, J. Anderson, H. W. Jun, M. A. Repka and S. Jo, Mol. Pharm., 2009, 6, 978-985.

176 J. C. Stendahl, M. S. Rao, M. O. Guler and S. I. Stupp, Adv. Funct. Mater., 2006, 16, 499-508.

45177 S. E. Paramonov, H. W. Jun and J. D. Hartgerink, Biomacromolecules, 2006, 7, 24-26.

178 H. A. Behanna, K. Rajangam and S. I. Stupp, J. Am. Chem. Soc., 2007, 129, 321-327.

179 A. Mata, L. Hsu, R. Capito, C. Aparicio, K. Henrikson and S. I.

50 Stupp, Soft Matter, 2009, 5, 1228-1236.

180 A. M. Hung and S. I. Stupp, Nano Letters, 2007, 7, 1165-1171.

181 R. N. Mitra and P. K. Das, J. Phys. Chem. C, 2008, 112, 8159-8166.

182 R. N. Mitra, D. Das, S. Roy and P. K. Das, J. Phys. Chem. B, 2007, 111, 14107-14113.

55183 S. Dutta, A. Shome, S. Debnath and P. K. Das, Soft Matter, 2009, 5, 1607-1620.

184 S. R. Bull, M. O. Guler, R. E. Bras, P. N. Venkatasubramanian, S. I. Stupp and T. J. Meade, Bioconjugate Chem., 2005, 16, 1343-1348.

185 M. O. Guler, L. Hsu, S. Soukasene, D. A. Harrington, J. F. Hulvat

60 and S. I. Stupp, Biomacromolecules, 2006, 7, 1855-1863.

186 M. O. Guler and S. I. Stupp, J. Am. Chem. Soc., 2007, 129, $12082-$ 12083.

187 H. W. Jun, S. E. Paramonov and J. D. Hartgerink, Soft Matter, 2006, 2, 177-181.

65188 J. P. Jung, J. L. Jones, S. A. Cronier and J. H. Collier, Biomaterials, 2008, 29, 2143-2151.

189 D. E. Discher, P. Janmey and Y.-1. Wang, Science, 2005, 310, 11391143.

190 I. Levental, P. C. Georges and P. A. Janmey, Soft Matter, 2007, 3, 299-306.
191 R. J. Pelham, Jr. and Y.-L. Wang, Proc. Nat. Acad. Sci., 1997, 94, 13661-13665.

192 J. Engler Adam, S. Sen, H. L. Sweeney and E. Discher Dennis, Cell, 2006, 126, 677-689.

75193 I. W. Hamley, A. Ansari, V. Castelletto, H. Nuhn, A. Rosler and H. A. Klok, Biomacromolecules, 2005, 6, 1310-1315.

194 J. Hentschel and H. G. Borner, J. Am. Chem. Soc., 2006, 128, 14142 14149.

195 H. R. Marsden, A. V. Korobko, E. N. M. van Leeuwen, E. M.

80 Pouget, S. J. Veen, N. Sommerdijk and A. Kros, J. Am. Chem. Soc., 2008, 130, 9386-9393.

196 M. Pechar, P. Kopeckova, L. Joss and J. Kopecek, Macromolecular Biosci., 2002, 2, 199-206.

197 G. W. M. Vandermeulen, C. Tziatzios and H. A. Klok, 85 Macromolecules, 2003, 36, 4107-4114.

198 C. Chun, H. J. Lim, K.-Y. Hong, K.-H. Park and S.-C. Song, Biomaterials, 2009, 30, 6295-6308.

199 H. J. Chung and T. G. Park, Nano Today, 2009, 4, 429-437.

200 S. Ganesh and R. Jayakumar, Biopolymers, 2003, 70, 336-345.

90201 H. A. Lashuel, S. R. LaBrenz, L. Woo, L. C. Serpell and J. W. Kelly, J. Am. Chem. Soc., 2000, 122, 5262-5277.

202 T. S. Burkoth, T. L. S. Benzinger, V. Urban, D. G. Lynn, S. C. Meredith and P. Thiyagarajan, J. Am. Chem. Soc., 1999, 121, 74297430.

95203 T. S. Burkoth, T. L. S. Benzinger, V. Urban, D. M. Morgan, D. M. Gregory, P. Thiyagarajan, R. E. Botto, S. C. Meredith and D. G. Lynn, J. Am. Chem. Soc., 2000, 122, 7883-7889.

204 J. M. Smeenk, M. B. J. Otten, J. Thies, D. A. Tirrell, H. G. Stunnenberg and J. C. M. van Hest, Angew. Chem. Int. Ed., 2005, 44, 1968-1971.

205 J. M. Smeenk, P. Schon, M. B. J. Otten, S. Speller, H. G. Stunnenberg and J. C. M. van Hest, Macromolecules, 2006, 39, 29892997. 